
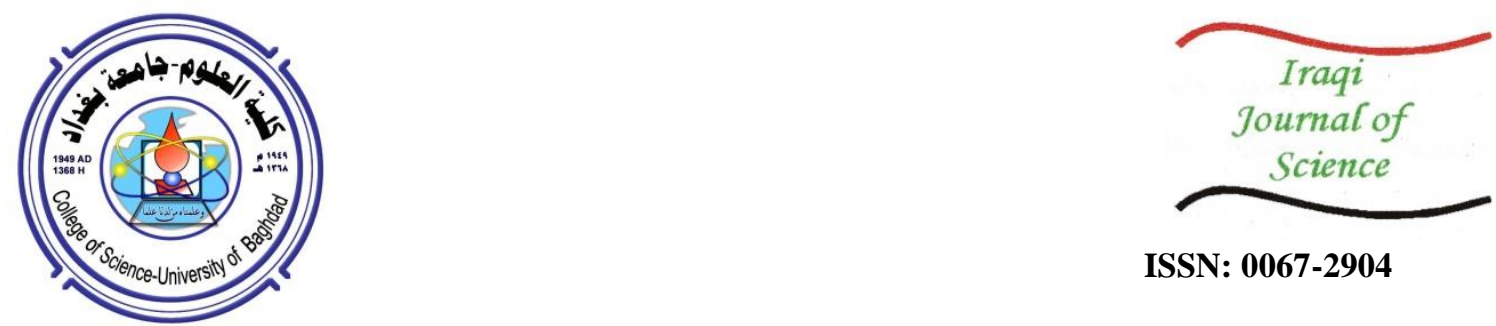

ISSN: 0067-2904

\title{
Influence of Acid Activation of a Mixture of Illite, Koalinite, and Chlorite Clays on the Adsorption of Methyl Violet 6B Dye
}

\author{
Saba Adil Saed , Dunya Edan AL-Mammar \\ Department of Chemistry, College of Science, University of Baghdad, Baghdad, Iraq
}

\begin{abstract}
The influence of acid activation of a mixture of illite, kaolinite, and chlorite clays collected from the area of Zorbatiya (east of Iraq) on the adsorption of methyl violet 6B (MV6B) as a cationic dye was studied. The activation was carried out by using $0.25 \mathrm{M} \mathrm{HCl}$ and $0.25 \mathrm{M} \mathrm{H}_{2} \mathrm{SO}_{4}$. Raw and acid-activated clays were analyzed by atomic force microscopy (AFM), scanning electron microscopy (SEM), and X-ray diffraction (XRD).

Batch adsorption method was used to study the adsorption of MV6B onto the raw and acid activated clays. The impacts of different factors on the adsorption process were studied, such as clay weight, agitation time, starting MV6B concentration, temperature, ionic strength, and solution $\mathrm{pH}$. The adsorption process was described by using Langmuir, Freundlich, Temkin, and Dubinin- Radushkevich isotherm models. Thermodynamic parameters like $\Delta \mathrm{H}^{\circ}{ }_{\mathrm{a}}, \Delta \mathrm{S}^{\circ}{ }_{\mathrm{a}}$, and $\Delta \mathrm{G}^{\circ}{ }_{\mathrm{a}}$ were estimated based on Van't Hoff equation.
\end{abstract}

Keywords: Adsorption MV6B dye, raw clay, acid activated clays.
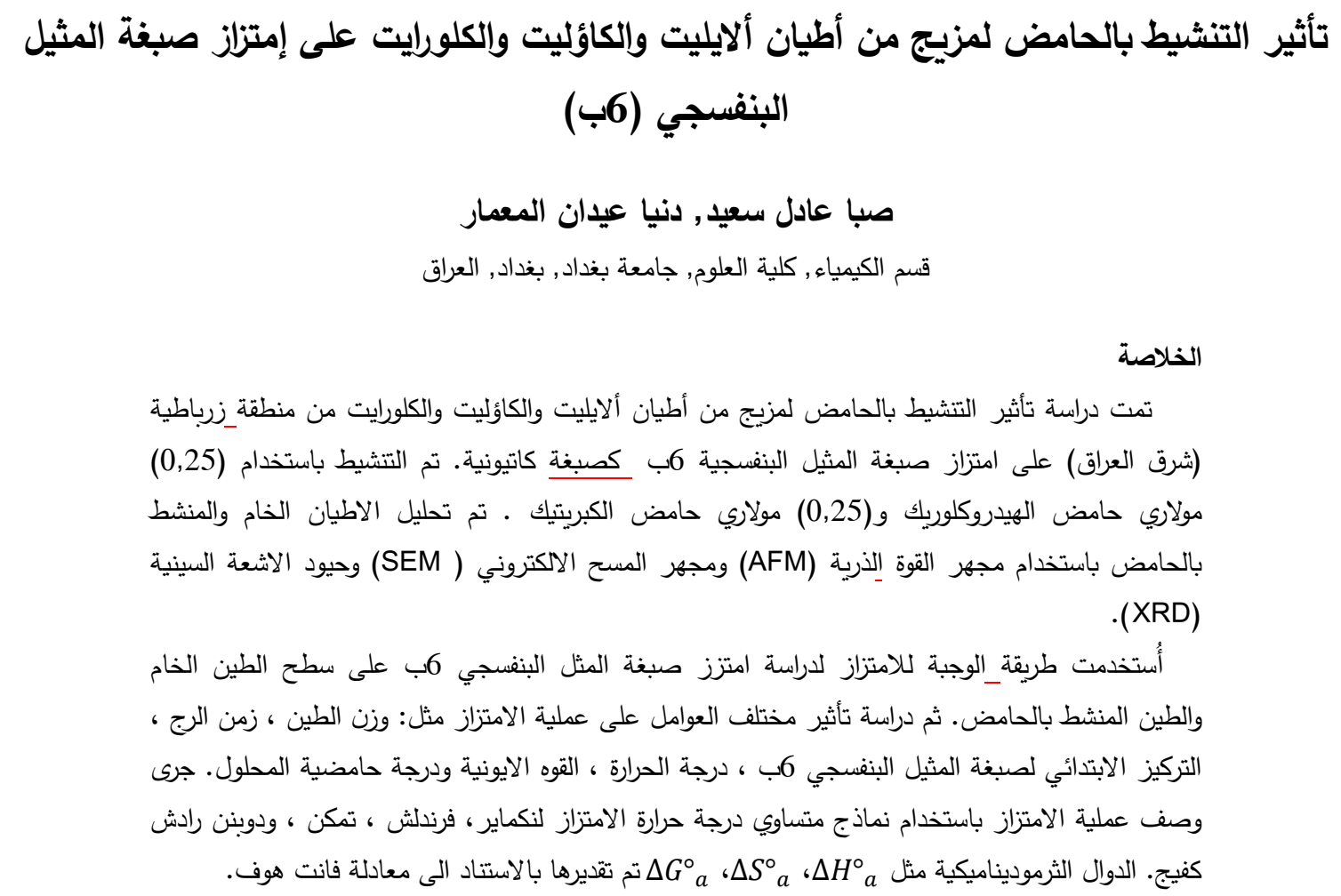

*Email: sabaadil314@yahoo.com 


\section{1- Introduction}

Dyes are organic colored substances used for coloring wool, textiles, paper, fibers, and leather [1]. Most of these dyes were designed to be resistant to the different environmental conditions, such as microbial attack and the effects of $\mathrm{pH}$ and light [2]. Also, small amounts of these substances in water were reported to cause dermatitis, allergy, mutations, and skin irritation for humans [3]. Therefore; the removal of these compounds from waste-effluents becomes a major issue. There are various chemical and physical processes which are available for the treatment of wastewater, including flocculation, ion-exchange precipitation, ozonation, and irradiation [4]. Among these different processes, adsorption should be one of the most effective techniques for the removal of color pollutants due to the cheapness, convenient operating conditions, and simple design [5]. There is a wide range of adsorbent materials employed for conditioning water, such as agricultural wastes [6], activated carbon, clay [7], and fly ash [8]. Using clays over commercially appropriate adsorbents have been well known, because they are abundant, non-toxic, and cost effective materials. Bentonite [9] reported that montmorillillonite, semectite, Kiolinite, and illite [10] were used for the deportation of toxic metals and dyes. The clays are often modified by a thermal [11] or chemical treatment [12] to enhance their adsorptive characteristic. The aim of this study is to investigate the influence of acid-activation with $\mathrm{HCl}$ and $\mathrm{H}_{2} \mathrm{SO}_{4}$ on the adsorption behaviors of a mixture of illite, kaolinite, and chlorite clays sampled from the region of Zorbatiya (east of Iraq).

\section{2-Materials and Methods}

\section{2-1- Materials}

Methyl violet 6B ( MV6B), a cationic dye with the chemical formula $\mathrm{C}_{23} \mathrm{H}_{26} \mathrm{~N}_{3} \mathrm{Cl}$ and molar mass of $379.94 \mathrm{~g} / \mathrm{mole}$, was provided from BDH. The molecular structure of the dye is illustrated in Figure1. This dye is widely used in textile, paints, and printing industries owing to its distinctive dark violet color [13].

Stock solution of $1000 \mathrm{mg} / \mathrm{L}$ was prepared by dissolving $1 \mathrm{~g}$ of MV6B in $1 \mathrm{~L}$ distilled water. This solution used for the preparation of the working solutions by dilution until obtaining the desired concentration.

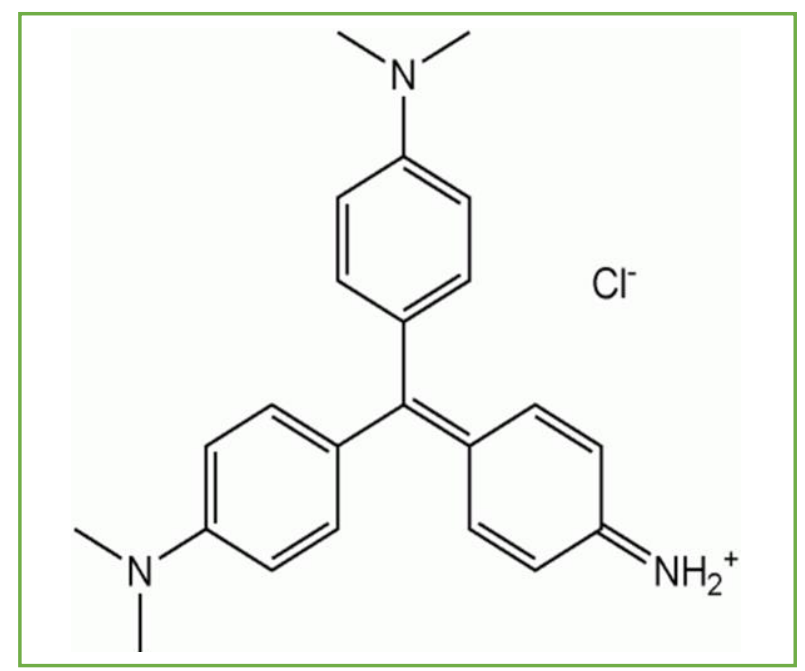

Figure 1- Chemical formula of methyl violet $6 \mathrm{~B}$ dye

The raw clay used in the study was collected from Zorbatiya area (east of Iraq). The clay has the following composition: $\mathrm{SiO}_{2} 19.6 \%, \mathrm{Al}_{2} \mathrm{O}_{3} 3.8 \%, \mathrm{Fe}_{2} \mathrm{O}_{3} 4.5 \%, \mathrm{C}_{\mathrm{a}} \mathrm{O} 15.2 \%, \mathrm{Mg}_{\mathrm{g}} \mathrm{O} .4 \%, \mathrm{~K}_{2} \mathrm{O} 1.3 \%$, $\mathrm{Na}_{2} \mathrm{O} 12.8 \%, \mathrm{TiO}_{2} 0.6 \%, \mathrm{P}_{2} \mathrm{O}_{5} 0.1 \%, \mathrm{SiO}_{3} 1.2 \%$, Cl $14.8 \%, \mathrm{M}_{\mathrm{n}} \mathrm{O} 0.38 \%$ and L.O.I. 19.6\%. The mineral analysis of this clay showed that it is a mixture of illite, kaolinite, and chlorite [14]. Acidification of the clays was performed by using $37 \%$ hydrochloric acid and $98 \%$ sulfuric acid supplied by Fluka.

\section{2-2-Methods}


$30 \mathrm{~g}$ of the raw clay was mixed with $100 \mathrm{ml}$ distilled water, followed by shaking for one hour at room temperature, and filtration by using Buckner funnel. The mixture was oven dried at $120^{\circ} \mathrm{C}$ for 7 hours, then allowed to cool and kept in a dry place. The obtained clay was labeled as RC.

\section{2-2-1- Activation with $\mathrm{HCl}$ and $\mathrm{H}_{2} \mathrm{SO}_{4}$}

To prepare acid-activated clay with $\mathrm{HCl}$, a weight of $20 \mathrm{~g}$ of the raw clay was mixed with $67 \mathrm{ml}$ $0.25 \mathrm{M} \mathrm{HCl}$ by using a thermostated shaker (Gallenkamp, England) for 2 hours. The resulting clay was filtered by using a Buckner funnel and the residue slurry was washed with distilled water until it became neutral. The prepared sample was dried at $120{ }^{\circ} \mathrm{C}$ for 2 hours and the activated clay was calcinated in muffle furnace (BS32C, Korea) at $750^{\circ} \mathrm{C}$ for 4 hours. The obtained clay was labeled as $\mathrm{ACH}$.

The acid-activated clay with $\mathrm{H}_{2} \mathrm{SO}_{4}$ was prepared by mixing $20 \mathrm{~g}$ of raw clay with $200 \mathrm{ml} 0.25 \mathrm{M}$ $\mathrm{H}_{2} \mathrm{SO}_{4}$ in a shaking water bath for 6 hours at $70^{\circ} \mathrm{C}$. Then, the sample was allowed to stand for fourteen hours in solution. Finally, the precipitate was filtered and washed for many times with distilled water till reaching a natural $\mathrm{pH}$. The sample was dried at $120^{\circ} \mathrm{C}$ for 2 hours, then calcinated at $750^{\circ} \mathrm{C}$ for 4 hours. The obtained clay was marked as ACS.

\section{2-3-Batch adsorption studies}

Batch experiments were carried out to study the adsorption of MV6B on RC and both acidactivated clays of $\mathrm{ACH}$ and ACS. A known quantity of the clay was added to $20 \mathrm{ml}$ dye solution in $100 \mathrm{ml}$ Erlenmeyer flask. The mixture was agitated by using a shaker with water bath (JTYS-1000, China) at pre- determined speed, time, and temperature. Centrifugation with $1000 \mathrm{rpm}$ was used for 5 min to separate the supernatant. The residual MV6B dye concentration was determined by UV-Vis Spectrophotometer ( Shimadzu UV 1800, Japan) at $\lambda_{\max }=583 \mathrm{~nm}$.

The removal percentage $\mathrm{R} \%$ and the amount of the MV6B dye adsorbed $Q_{e}$ were calculated by using equations:

$$
\begin{aligned}
\mathrm{R} \% & =100\left[\frac{\mathrm{C}_{\mathrm{s}-} \mathrm{C}_{\mathrm{e}}}{\mathrm{C}_{\mathrm{s}}}\right] \\
\mathrm{Q}_{\mathrm{e}} & =\frac{\mathrm{V}}{\mathrm{M}}\left[\mathrm{C}_{\mathrm{s}}-\mathrm{C}_{\mathrm{e}}\right]
\end{aligned}
$$

where $Q_{e}(\mathrm{mg} / \mathrm{gm})$ is the amount of MV6B dye adsorbed on the clays at equilibrium, $C_{s}, C_{e}$ are the starting concentration and the concentration at equilibrium $(\mathrm{mg} / \mathrm{L})$, respectively, $\mathrm{V}$ is the volume of the working solution (L), and $\mathrm{M}$ is the mass of the clay ( $\mathrm{g}$ ).

\section{Results and discussion}

\section{3- Characterization}

\section{3-1- Morphology}

\section{3-1-1- Atomic force microscopy}

The measurements of the average grain size were performed by AFM examination. Figures- 2, 3, and 4 display a typical surface from AFM images (in three dimensions), and the granularity cumulating distribution for three types of clays. The average diameter values for $\mathrm{RC}, \mathrm{ACH}$, and ACS were $160.52 \mathrm{~nm}, 106.81 \mathrm{~nm}$, and $92.75 \mathrm{~nm}$ ), respectively. This indicates that the particle size of the acid-activated clays is smaller than that of the raw clay, which leads to increase the specific surface area for both ACH and ACS clays.
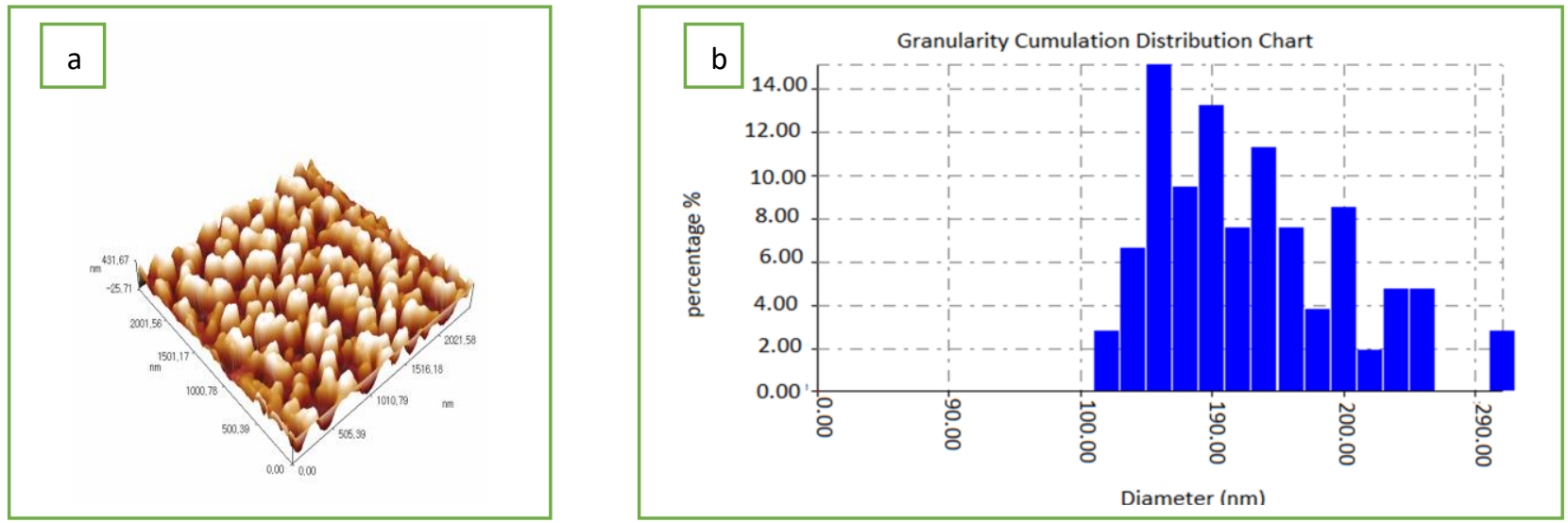

Figure 2 a- View of AFM image of RC; b: Granularity cumulating distribution chart of RC. 

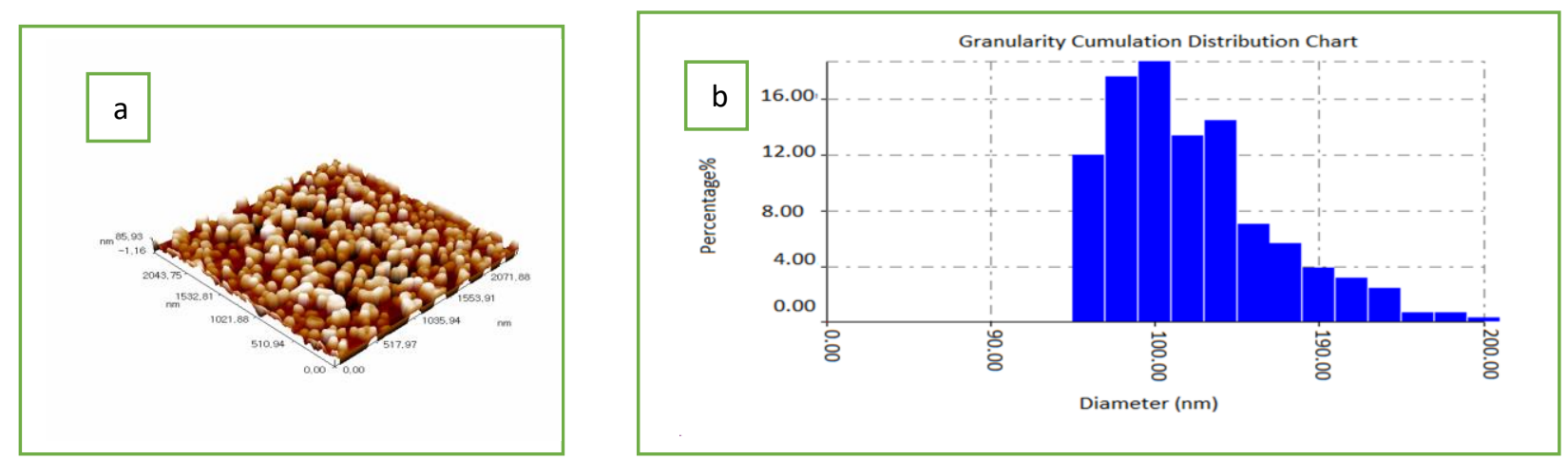

Figure 3- a View of AFM image of ACH; b: Granularity cumulating distribution chart of ACH.
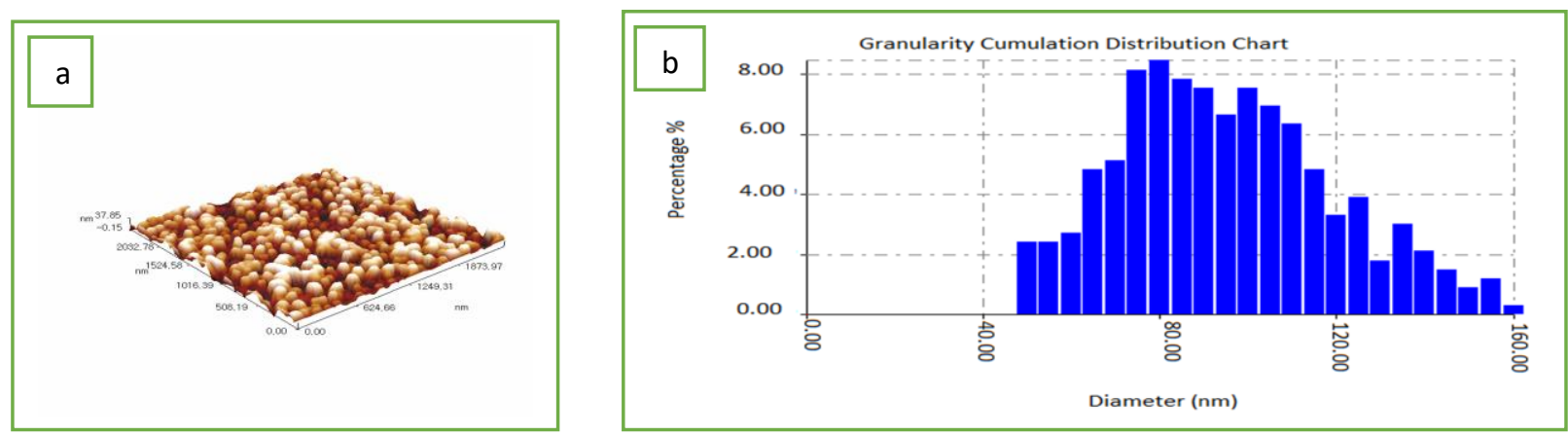

Figure 4 a- View of AFM image of ACS; b: Granularity cumulating distribution chart of ACS.

\section{3-1-2- Scanning electron microscopy}

The RC and acidactivated clay samples were tested under scanning electron microscopy (ZEISS Gemini-Germany) to explore the morphology, surface features, crystalline structure, and porosity. As shown in Figure -5 ( $a, b$ and $c)$, the acid-activated clays with both $\mathrm{HCl}$ and $\mathrm{H}_{2} \mathrm{SO}_{4}$ are more porous than the raw clay. This may be attributed to the cation leaching from the clay surface in the course of its activation with acids, which creates voids on the clay, hence the clay surface becomes highly porous [15]. Also, this figure shows flake clustered particles with a smooth irregular surface [10].
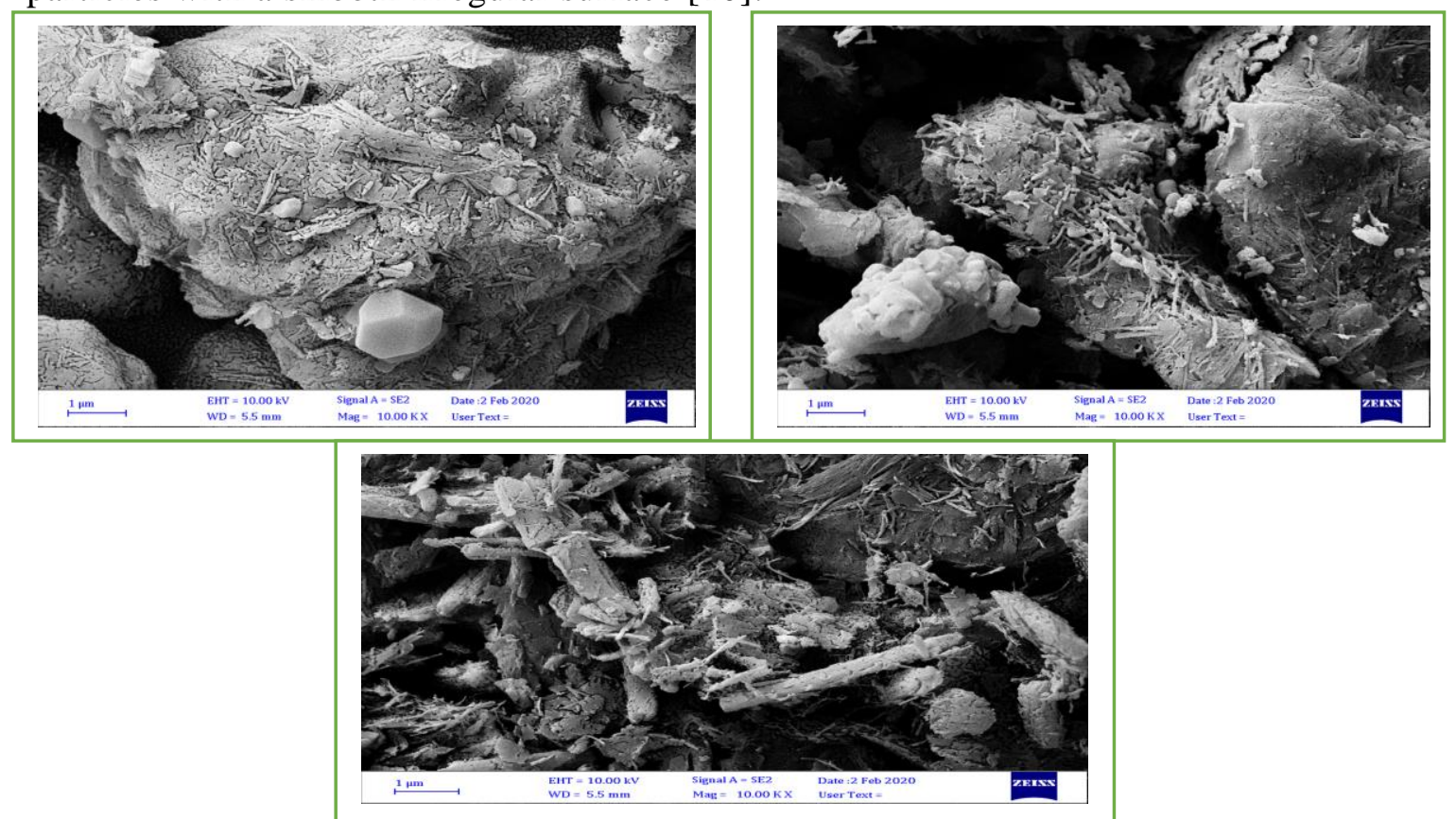

Figure 5- SEM images of clays surfaces for (a) RC, (b) ACH, and (c) ACS. 


\section{3-2- X-Ray diffraction}

The XRD analysis was carried out by using x-ray diffraction detector(PNA analysis, XRD-UK). Figure- 6 (a, b and c) shows the XRD shapes for clay samples. It is obvious from Figure- 6(a) that the diffraction shape displays the existence of peaks related to quartz $(2 \Theta=26.637,50.100$ degrees $)$, calcite $(2 \Theta=29.412,39.400,47.540$ degrees $)$, kaolinite $(2 \Theta=12.487,24.321$ degrees $)$, and illite $(2 \Theta=35.990$ degree). While for the acid-activated clay shown in Figure- $6(b, c)$, the peaks of kaolinite and illite become unimportant and the peaks of quartz and calcite become more concentrated [16].
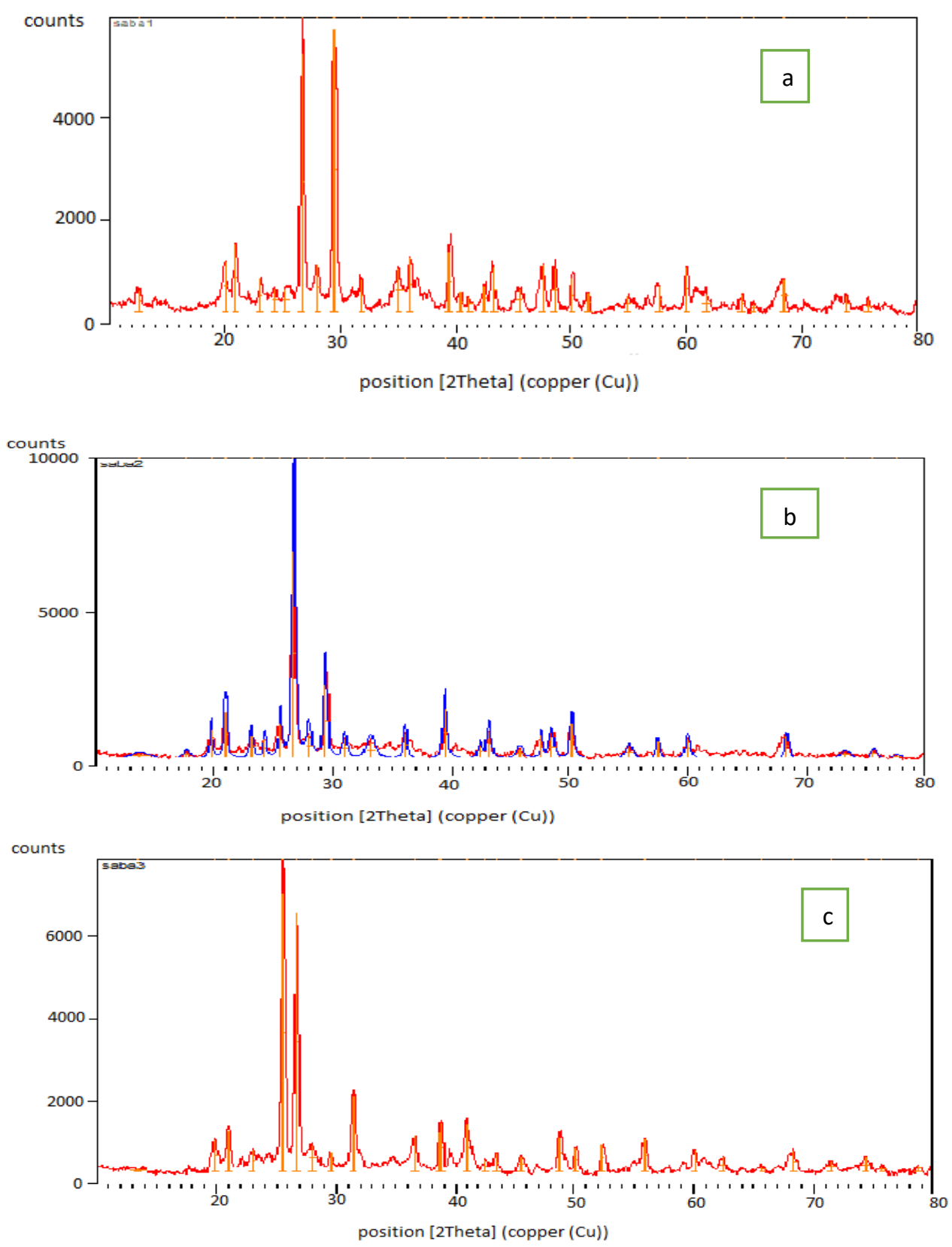

Figure 6-X- ray diffraction investigations of (a) RC, (b) ACH, and (c) ACS.

\section{4- Influence of various parameters on MV6B adsorption \\ 4-1- Influence of clay dosage}

The influence of clay dosage on the removal of MV6B dye from RC, ACH, and ACS clays was tested by using various amounts of clay (in the range of $0.025-0.5 \mathrm{~g}$ ) and $20 \mathrm{ml}$ of $10 \mathrm{mg} / \mathrm{L}$ MV6B dye at $293 \mathrm{~K}, \mathrm{pH} 7$, and shaking speed of $150 \mathrm{rpm}$. As shown in Figure-7, the removal percentage for the three types of clay increased from 6.35 to $96.62 \%$ for RC and from 7.7 and $8.7 \%$ to 99.1 and $99.72 \%$ for $\mathrm{ACH}$ and ACS, respectively, with the increase in clay dosage. Thus, in the higher dosage, the clay provides more active surface sites [19]. However, further increasing the clay weight did not show any 
increase in the removal percentage. This is due to the overlapping between the active sites at high amounts of adsorbent. Similar results were reported by Zhang et al. [20]. Therefore, $0.1 \mathrm{~g}$ of clay was selected as an optimum dosage.

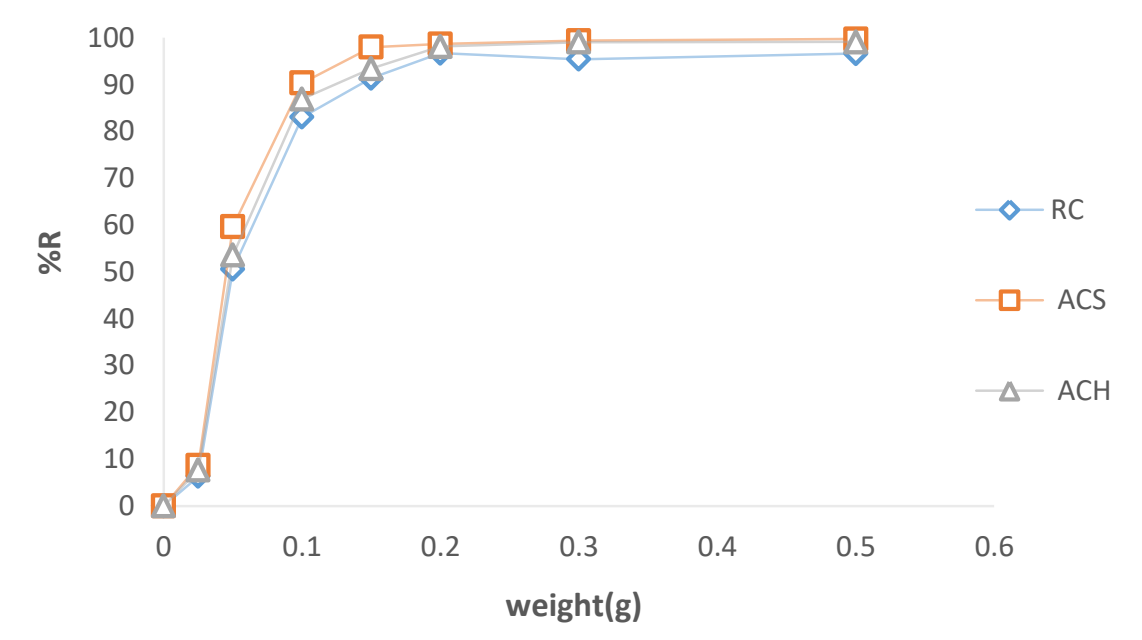

Figure 7- Influence of clay dosage on the removal percentage (R\%) of MV6B dye.

\section{4-2- Influence of agitation time}

The influence of agitation time on the removal percentage of $10 \mathrm{mg} / \mathrm{L} \mathrm{MV6B}$ dye by using raw and acid activated clays was tested at $\mathrm{pH} \mathrm{7}$, range of time of 5-60 $\mathrm{min}$, temperature of $293 \mathrm{~K}$, clay dosage of $0.1 \mathrm{~g}$, and agitation speed of $150 \mathrm{rpm}$. It is clear from Figure- 8 that the removal percentage suddenly increases at $5 \mathrm{~min}$ and then onwards a steady state is reached. This may be attributed to the obtainability of empty adsorption sites on the surface of the clay, which is slowly increased until reaching equilibrium [13]. Thus, the optimum time chosen was $45 \mathrm{~min}$.

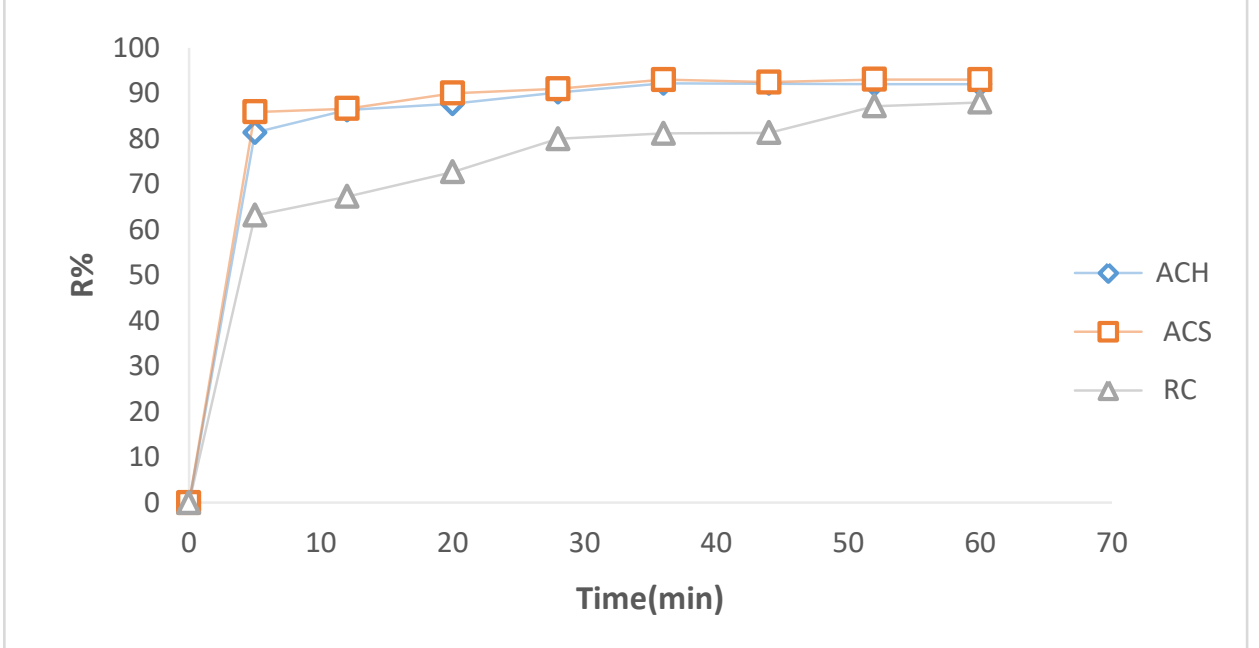

Figure 8- Influence of agitation time on the adsorption of MV6B dye onto raw and acid activated clays.

\section{4-3- Influence of starting dye concentration}

The influence of starting MV6B concentration was tested at the following conditions: dye concentration ranging 10,20,30,35, and $40 \mathrm{mg} / \mathrm{L}$, clay dosage of $0.1 \mathrm{~g}, \mathrm{pH} \mathrm{7}$, temperature of $293 \mathrm{~K}$, agitation time of $45 \mathrm{~min}$, and shaking speed of $150 \mathrm{rpm}$. It is obvious from Figure-9 that as MV6B concentration starts to change from 10 to $40 \mathrm{mg} / \mathrm{L}$, R\% values change from 80.24 to 65.38 for raw clay and from 82.1 and 85.01 to 66.23 and 66.73 for the acid activated clays of ACH and ACS. These results may be accounted to that, at low MV6B dye concentration, sufficiently available active sites are present on the clay surfaces, while upon increasing dye concentration, the demand for active sites is higher, but the available ones are limited [21]. 


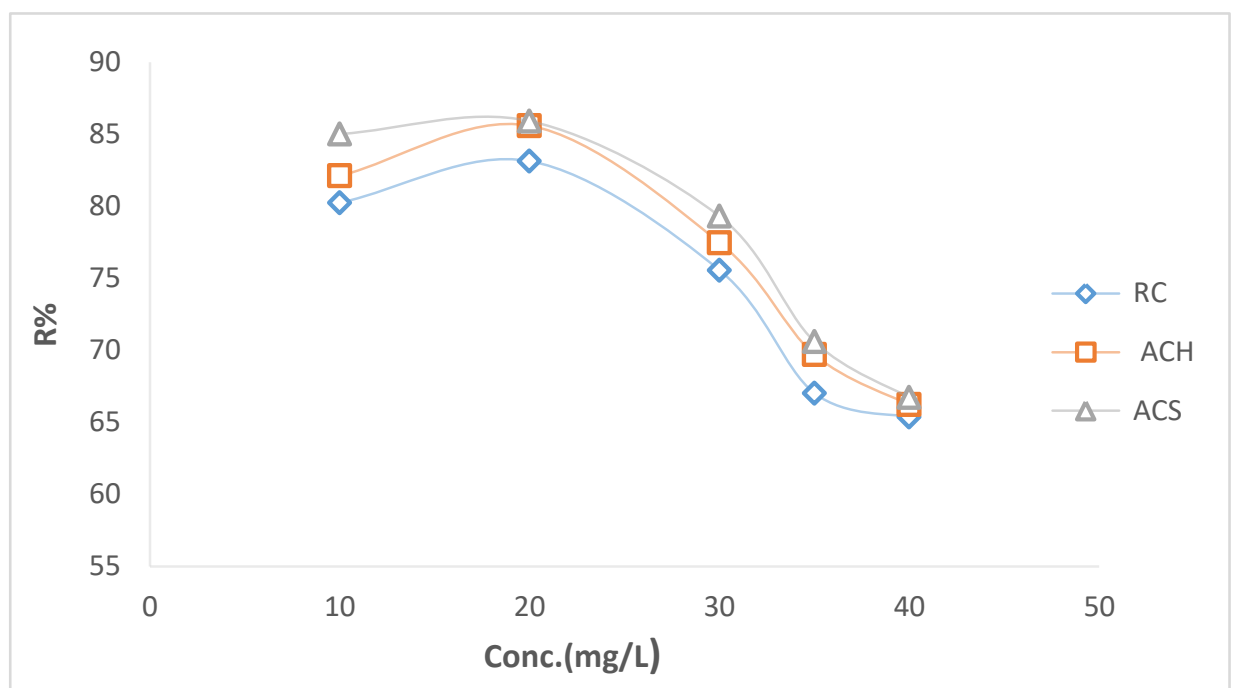

Figure 9- Influence of starting MV6B concentration on the adsorption of MV6B dye onto RC and acid activated clays.

\section{4-4- Temperature influence}

The temperature influence on the percentage removal of MV6B was examined by changing the temperature from $288 \mathrm{~K}$ to $328 \mathrm{~K}$ at the following optimum conditions: starting concentration of MV6B $10 \mathrm{mg} / \mathrm{L}, \mathrm{pH} 7$, clay dosage of $0.1 \mathrm{~g}$, time for equilibrium of $45 \mathrm{~min}$, and shaking speed of $150 \mathrm{rpm}$. The results are depicted in Figure-10. It can be reported that the R\% increased with rising temperature, which reflects the endothermic nature for the adsorption process.

The noted influence refers to an increase in the mobility of the MV6B dye that leads to an increase in the number of active adsorption sites with rising temperature. This may causes an increase in the number of molecules that have sufficient energy for the interaction with the active surface sites. Additionally, when temperature increases, it causes swelling in the internal structure of clay, which allows for a large dye molecules to penetrate the surface of clay [21].

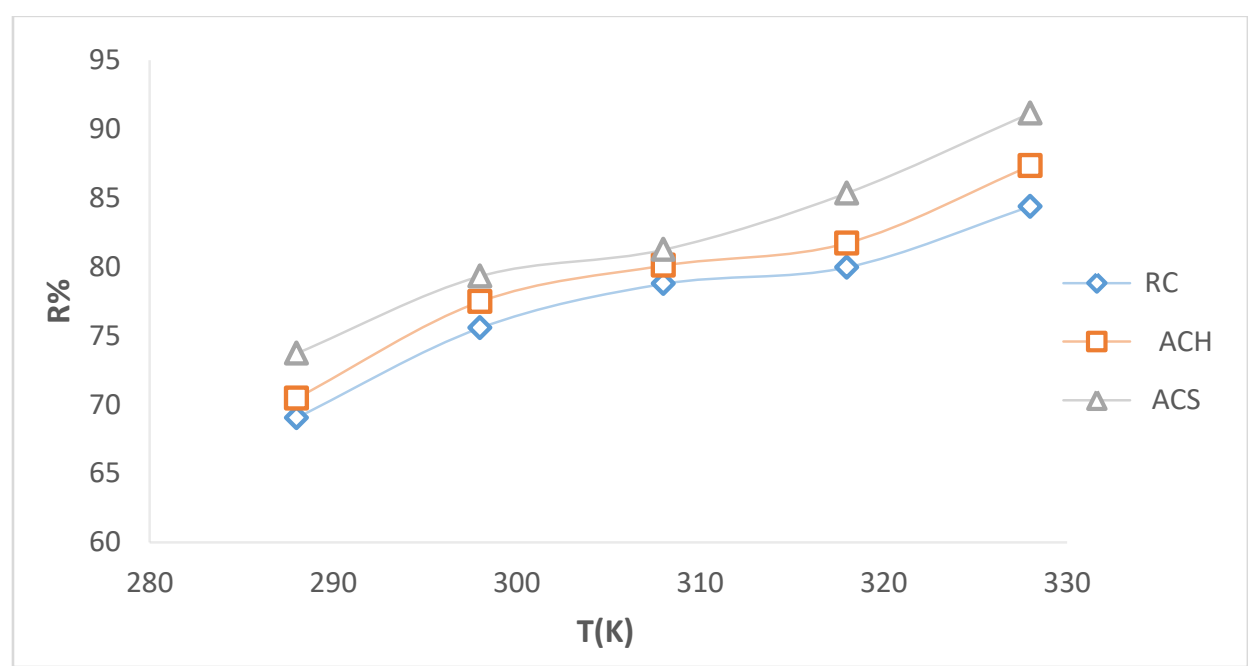

Figure 10- Temperature influence on the adsorption of MV6B onto different adsorbents.

\section{4-5- Influence of solution ionic strength}

The impact of ionic strength on the MV6B adsorption was studied by adding sodium chloride salt within the range of $0.2-1.0 \mathrm{mg} / \mathrm{L}$, with a starting MV6B concentration of $10 \mathrm{mg} / \mathrm{L}$, clay dosage of 0.1 $\mathrm{g}, \mathrm{pH} 7$, shaking time of $45 \mathrm{~min}$, temperature of $293 \mathrm{~K}$ and shaking speed of $150 \mathrm{rpm}$. Figure- 11(a) indicates that the R\% of MV6B dye onto raw clay is decreased when the concentration of $\mathrm{NaCl}$ is increased. This phenomenon can be ascribed for two factors; first, the cation of $\mathrm{Na}^{+}$contest with the cations of the dye on the negatively charged sites in the adsorbent surface; second, the $\mathrm{Cl}^{-}$ions 
counterbalance the cationic charge of the dye molecules and shield the electrostatic attraction between them and the anionic clay surfaces. As a result, the adsorption of cationic dyes onto the negatively charged sites of clay surfaces is inhibited by high concentrations of $\mathrm{NaCl}$ [13]. Figure11(b) shows that the R\% of the absorption of MV6B dye onto acid activated clays is increased with the increase in the concentration of $\mathrm{NaCl}$. This may be related to the accumulation of cations of MV6B dye persuaded by the action of salt ions. Several types of intermolecular forces were proposed to affect this aggregation, including van der Waals, ion dipole, and dipole-dipole forces. These forces occur between dye molecules in the solution and they are increased when $\mathrm{NaCl}$ salt is added to the MV6B solution [22].

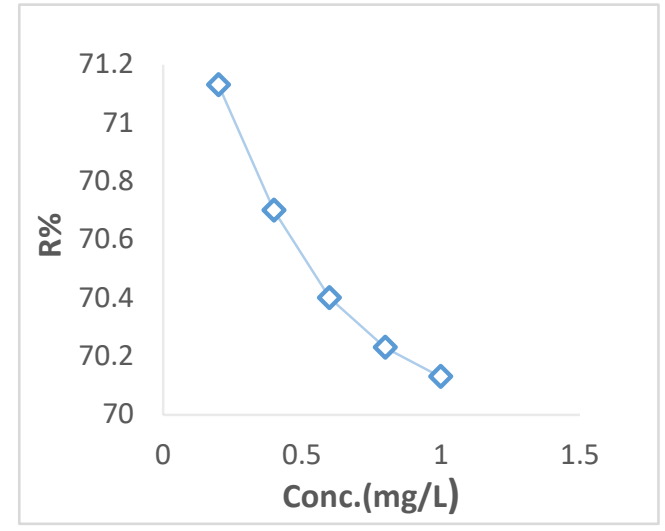

(a)

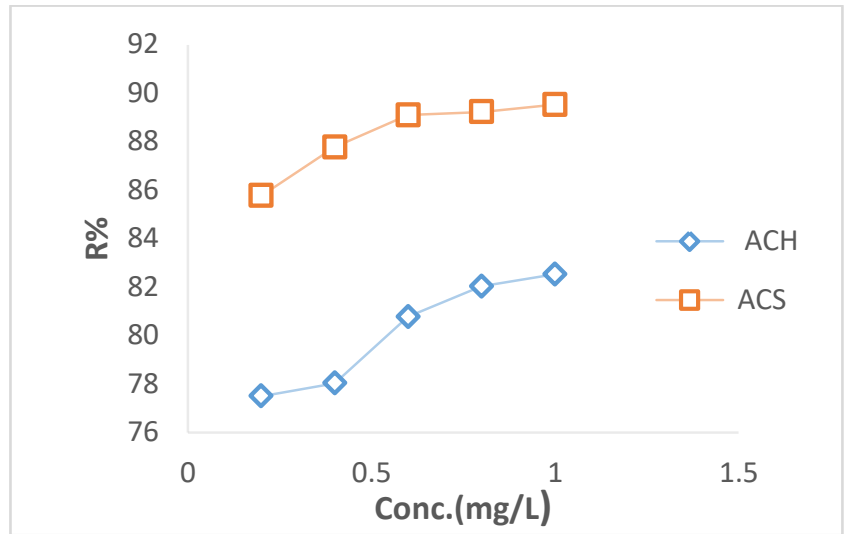

(b)

Figure 11- Influence of ionic strength on the adsorption MV6B onto (a) RC; (b) ACH and ACS.

\section{4-6- Influence of initial pH}

The impact of $\mathrm{pH}$ was investigated in the course of its variation between 1.67 and 11 at $293 \mathrm{~K}$, starting concentration of $10 \mathrm{mg} / \mathrm{L}, 0.1 \mathrm{~g}$ clay dosage, agitation time equal to $45 \mathrm{~min}$, and shaking speed equal to $150 \mathrm{rpm}$. The $\mathrm{pH}$ of the solution was adjusted by using $1 \mathrm{M} \mathrm{HCl}$ and $1 \mathrm{M} \mathrm{NaOH}$, was and the results are illustrated in Figure-12. It is evident that the percentage of the adsorption of MV6B dye onto $\mathrm{RC}, \mathrm{ACH}$, and ACS increases with increasing the $\mathrm{pH}$ of the solution. The low value of $\mathrm{R} \%$ for these clays at low $\mathrm{pH}$ is related to the competition between the MV6B ions and hydrogen ions for the acid. If the $\mathrm{pH}$ values exceed 7, the $\mathrm{R} \%$ is growing rapidly till it reaches 70.69 for $\mathrm{RC}$ and 73.26 and 79.49 for ACH and ACS, respectively. Hence, it is clear that the MV6B produces cations in the aqueous medium. Thus, the adsorption of the cationic dye on the clays surfaces is primarily affected by the charge of the clay surface. At lower $\mathrm{pH}$, there is an electrostatic repulsion between the MV6B ions and the positive charge groups on the clay surfaces, while at a higher $\mathrm{pH}$, the clay surface becomes negative that leads to decrease the electrostatic repulsion and, hence, the dye cations in solution can be attracted to the surface [17].

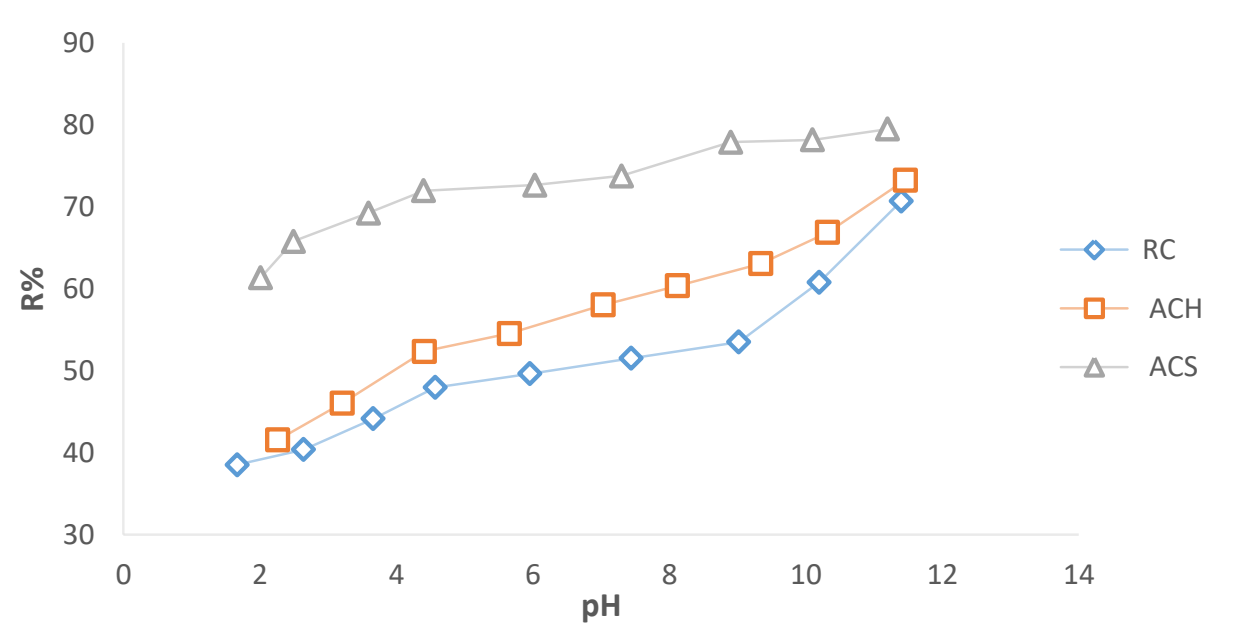

Figure 12- Influence of $\mathrm{pH}$ on the adsorption of MV6B dye onto raw clay and acid activated clays. 


\section{5- Isotherm modeling}

The adsorption was analyzed by using Langmuir, Freundlich, Temkin and Dubinin-Radushkevich models.

\section{5-1- Langmuir isotherm}

The Langmuir isotherm model postulates the maximum adsorption of a saturated monolayer of solute molecules on the adsorbent surface. The linear form of Langmuir model is [23]:

$$
\frac{\mathrm{Ce}}{\mathrm{Qe}}=\frac{1}{\mathrm{Qm} \cdot \mathrm{k}_{\mathrm{L}}}+\frac{1}{\mathrm{Qm}} \text {. Ce- }
$$

$\mathrm{Q}_{\mathrm{m}}(\mathrm{mg} / \mathrm{g})$ and $k_{L}(\mathrm{~L} / \mathrm{mg})$ are the Langmuir constants associated to adsorption capacity and rate of adsorption, respectively, and resolute from the linear plot of specific adsorption $C_{e} / Q_{e}$ against the equilibrium concentration $\mathrm{C}_{\mathrm{e}}$. Figure-13 shows the Langmuir isotherm plots for the adsorption of MV6B onto the raw and acid activated clays. These values are listed in Table-1. There is a marked increase in the values of the adsorption capacity $Q_{m}$ for the acid activated clays, which means that the activation improved the adsorption capacity for the raw clay. The ACS shows the optimal adsorption capacity $Q_{m}$, which is evidently higher than those of the ACH and RC samples. This confirms that the generation of more total binding sites leads to increase the porosity [24]. The significant feature of the Langmuir isotherm can be exhibited by Rs, a dimensionless equilibrium parameter or separation factor. $R_{s}$ values are calculated from the equation $R_{S}=\frac{1}{1+K_{L} \cdot C_{o}}$. When the value of $R_{S}$ is between 0 and 1 , then the adsorption is favorable, while at $R_{S}>1$ the adsorption is unfavorable, $R_{S}=0$ reflects irreversible adsorption, and $R_{s}=1$ indicates linear adsorption. Table- 2 shows the values of $1>R_{s}>0$ for all samples, which indicates that the adsorption of MV6B dye onto clays is favorable [25].
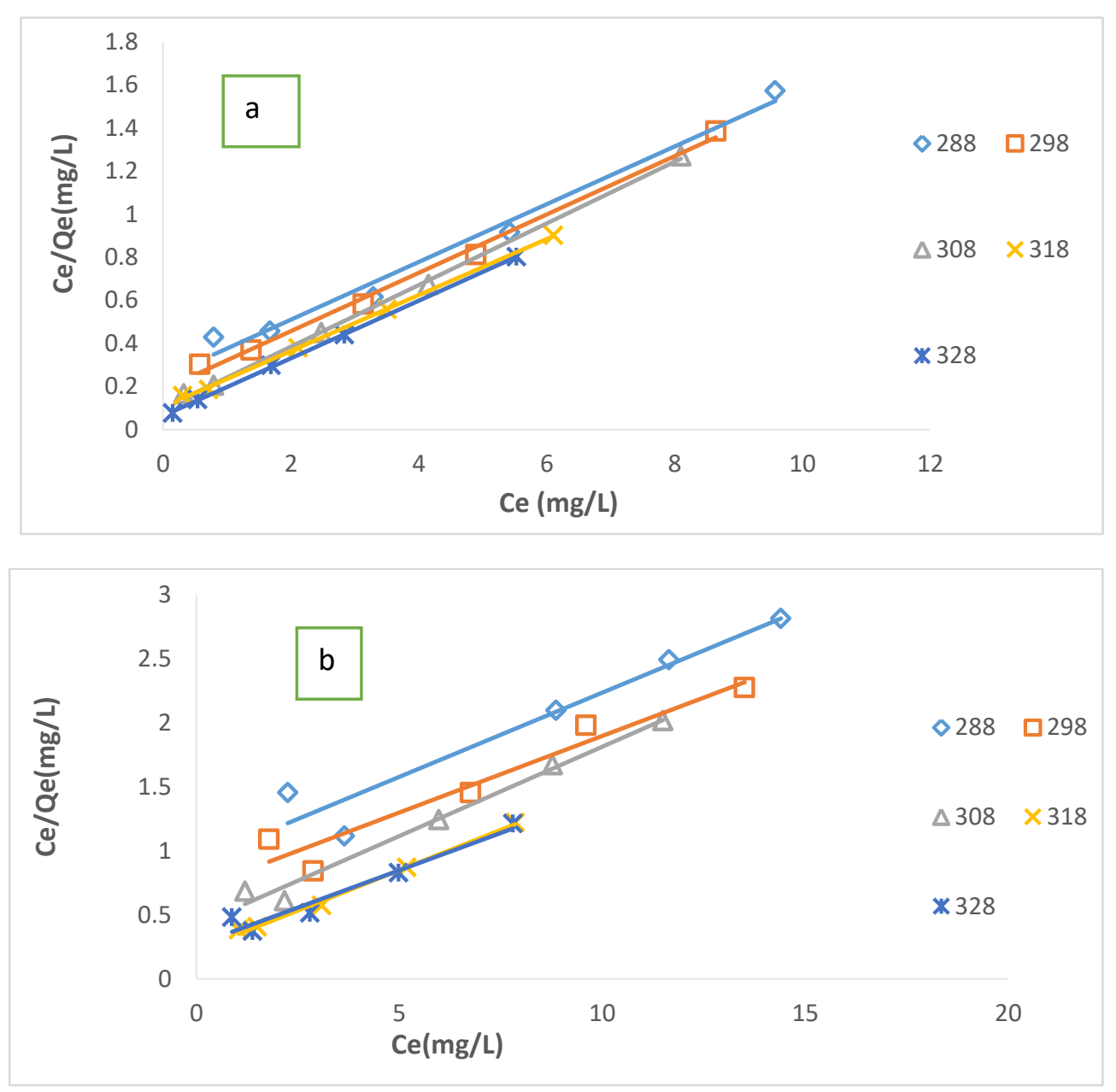


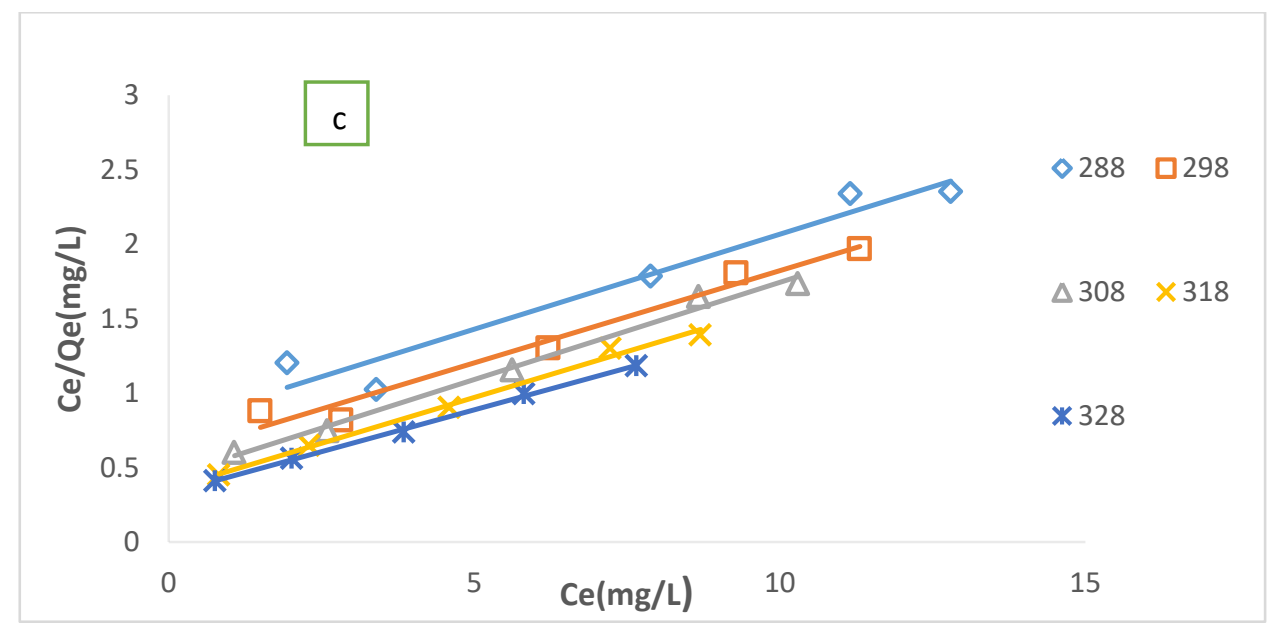

Figure 13- Langmuir isotherm plots for the adsorption of MV6B dye onto (a) RC, (b) ACH, and (c) ACS at different temperatures.

\section{5-2- Freundlich isotherm}

Freundlich model assumes that MV6B adsorption takes place on sites with various adsorption energies or at heterogeneous clay surfaces. It is usually written as [26]:

$$
\operatorname{Ln} \mathrm{q}_{\mathrm{e}}=\mathrm{LnK}_{\mathrm{f}}+\frac{1}{\mathrm{n}_{\mathrm{f}}} \operatorname{Ln} \mathrm{C}_{\mathrm{e}}
$$

where $K_{f}$ and $n_{f}$ are freundlich constants related to adsorption capacity and adsorption intensity, respectively. The values of these constants were estimated from the intercept and slope of the plot between $\mathrm{Ln} \mathrm{q}_{\mathrm{e}}$ vs Ln C $\mathrm{e}_{\mathrm{e}}$ (Figure-14), as illustrated in Table-1. The value of $n_{f}$ identifies the favorability of the sorption process. If it is within the range of $1<\mathrm{n}_{\mathrm{f}}<10$, then the adsorption is favorable [18]. From the listed values of $n_{f}$, it is clear that it lies in the range of $1-10$, verifying a favorable adsorption process.

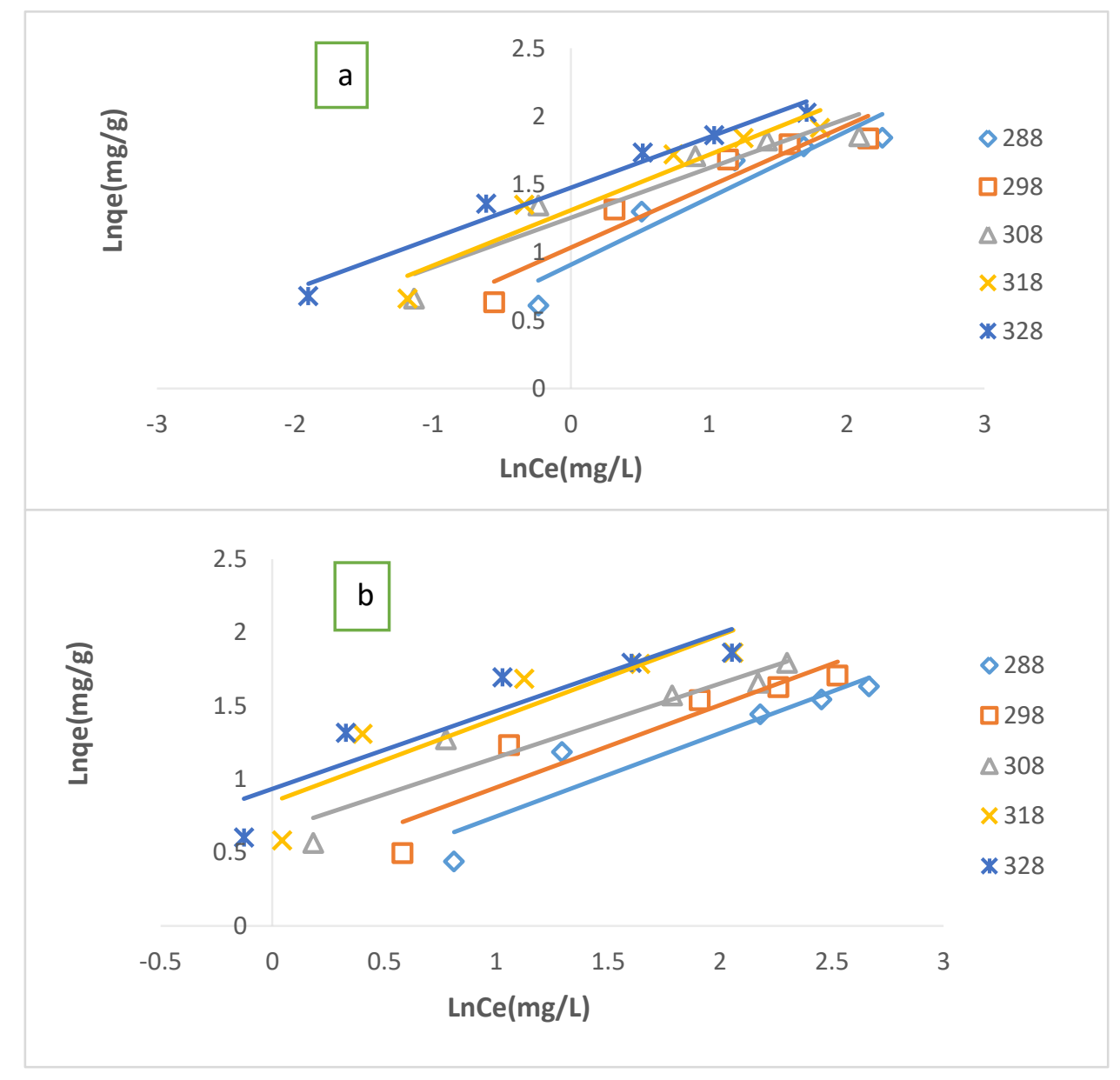




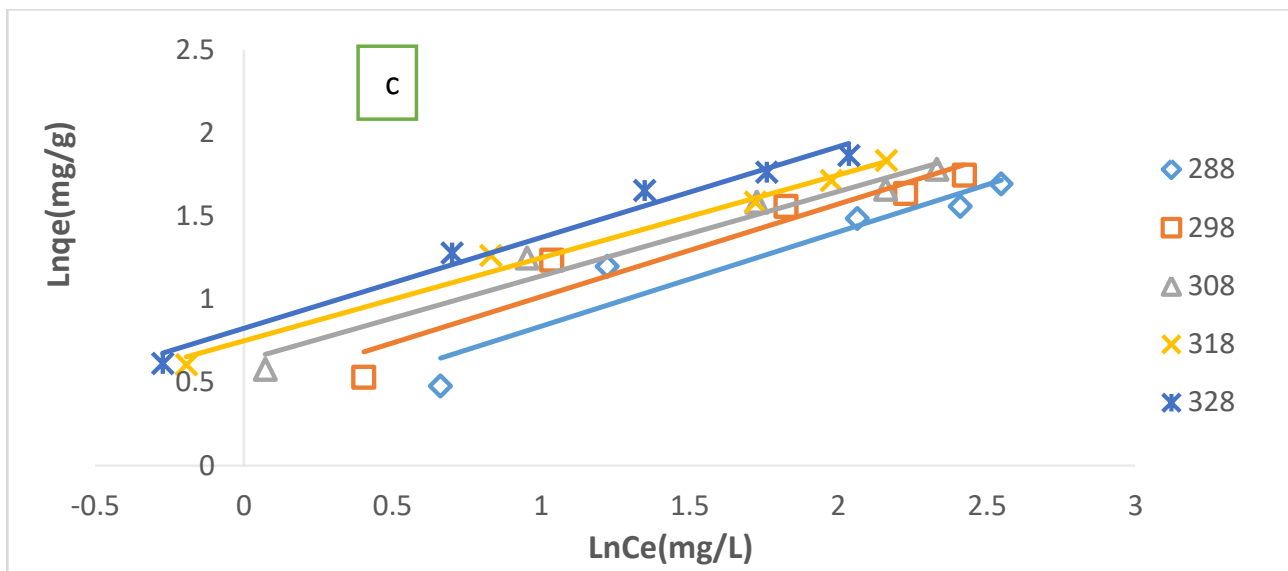

Figure 14- Freundlich isotherm plots for the adsorption of MV6B dye onto (a) RC, (b) ACH, and (c) ACS at different temperatures.

\section{5-3- Temkin model}

This model is based on the effects of the indirect dye- clay interactions on sorption. The heat of adsorption is decreasing linearly with the surface coverage [23]. The linear equation for Temkin isotherm is expressed as [18]:

\[ Q_{e}=B_{T} \operatorname{Ln} A_{T} \]
where $A_{T}$

$$
\mathrm{Q}_{\mathrm{e}}=\mathrm{B}_{\mathrm{T}} \operatorname{Ln} \mathrm{A}_{\mathrm{T}}+\mathrm{B}_{\mathrm{T}}(\operatorname{LnCe})
$$

$\mathrm{B}_{\mathrm{T}}=\frac{\mathrm{RT}}{\mathrm{b}_{\mathrm{T}}},\left(\mathrm{b}_{\mathrm{T}}\right.$ in mol . $\left.\mathrm{KJ}^{-1}\right)$, is Temkin constant related to heat of adsorption.

$\mathrm{R}=$ universal gas constant $\left(8.314 \mathrm{~J} \cdot \mathrm{mol}^{-1} \cdot \mathrm{K}^{-1}\right)$. $\mathrm{T}=$ absolute temperature $(\mathrm{K})$.

The constants $A_{T}$ and $b_{T}$ are evaluated from the intercept and slope of the linear plot of $Q_{e} v s$. $L n C_{e}$. The obtained values are listed in Table- 1 . The positive values of $b_{T}$ noted that the adsorption process is endothermic. The values of $\mathrm{B}_{\mathrm{T}}<8 \mathrm{KJ} / \mathrm{mol}$ indicate weak interaction between MV6B ions and clay samples surfaces, thus indicating that the adsorption is likely physisorption [25].

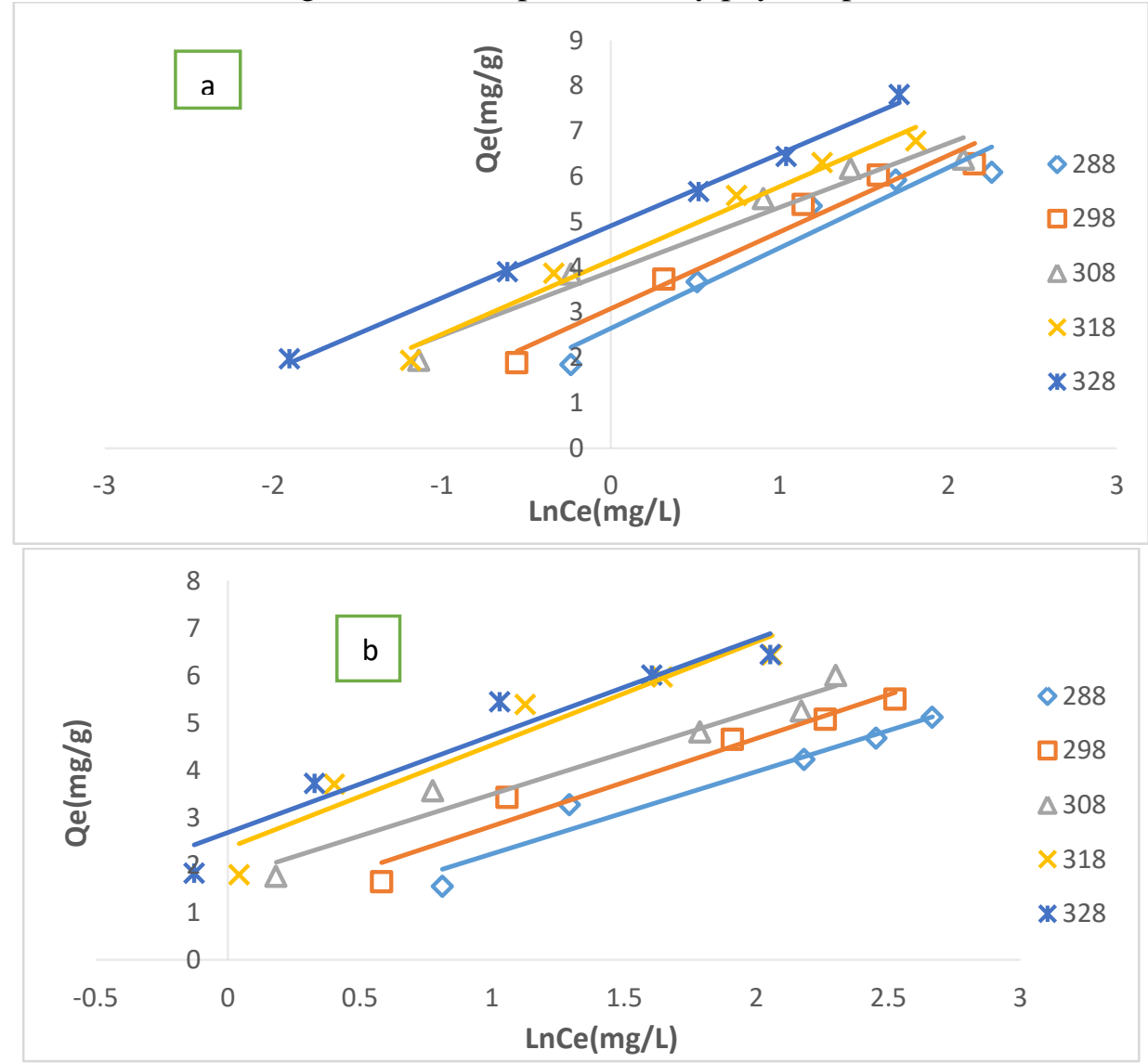




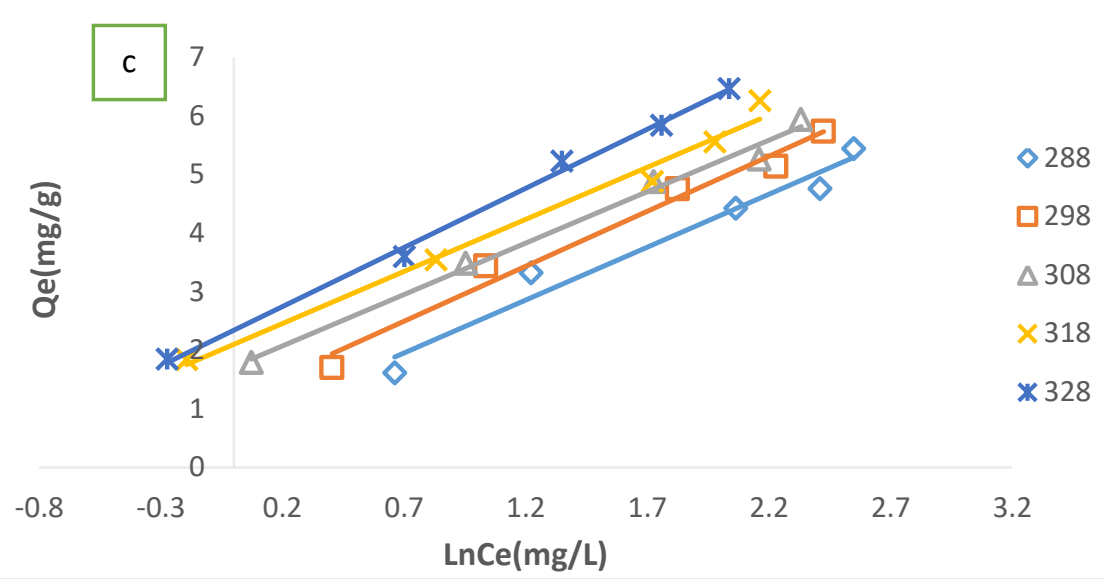

Figure15-Temkin isotherm plots for the adsorption of MV6B dye onto (a) RC, (b) ACH, and (c) ACS at different temperatures.

\section{5-4- Dubinin-Radushkevich (D-R) isotherm}

The Dubinin-Radushkevich isotherm was applied to study the adsorption on microporous materials based on the potential theory of adsorption. The linear form of D-R model is:

$$
\mathrm{LnQ}_{\mathrm{e}}=\mathrm{LnK}_{\mathrm{D}-\mathrm{R}}-\mathrm{BE}{ }^{2}
$$

where B: activity coefficient related to the mean adsorption energy $\left(\mathrm{mole}^{2} / \mathrm{KJ}^{2}\right)$.

$\mathrm{K}_{\mathrm{D}-\mathrm{R}}$ : maximum adsorption capacity $(\mathrm{mg} / \mathrm{g})$.

$\varepsilon$ : polanyi potential calculated by using the equation $\varepsilon=\mathrm{RT} \operatorname{Ln}\left[1+1 / C_{e}\right]$.

The adsorption energy $\mathrm{E}(\mathrm{J} / \mathrm{mole})$ is calculated by $\mathrm{E}=-\frac{1}{(2 \mathrm{~B})^{0.5}}$.

When the value of $\mathrm{E}<8 \mathrm{KJ} /$ mole, the adsorption process is physical, whereas at $\mathrm{E}>8 \mathrm{KJ} / \mathrm{mole}$, the adsorption process is a chemisorption. The D-R parameters were calculated from the slope and intercept of $\mathrm{LnQ}_{\mathrm{e}}$ vs. $\mathcal{E}^{2}$ and the values are given in Table-1. The value of $\mathrm{E}$ is almost lower than $8 \mathrm{KJ} / \mathrm{mol}$. It verifies that the MV6B adsorption on $\mathrm{RC}, \mathrm{ACH}$, and $\mathrm{ACS}$ is a physical one [25]. It is obvious that Langmuir isotherm described better the dye uptake, with the higher correlation coefficient $\mathrm{R}^{2}$ values, for the $\mathrm{RC}, \mathrm{ACH}$, and $\mathrm{ACS}$ samples in comparison with that of the other adsorption isotherm models.

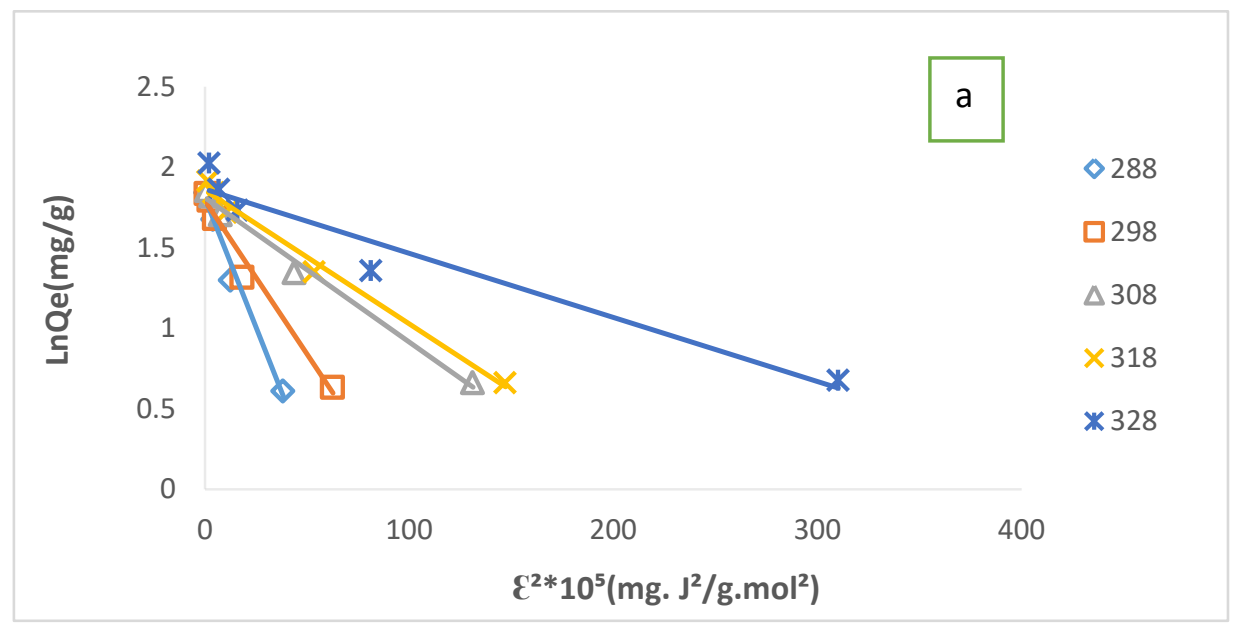



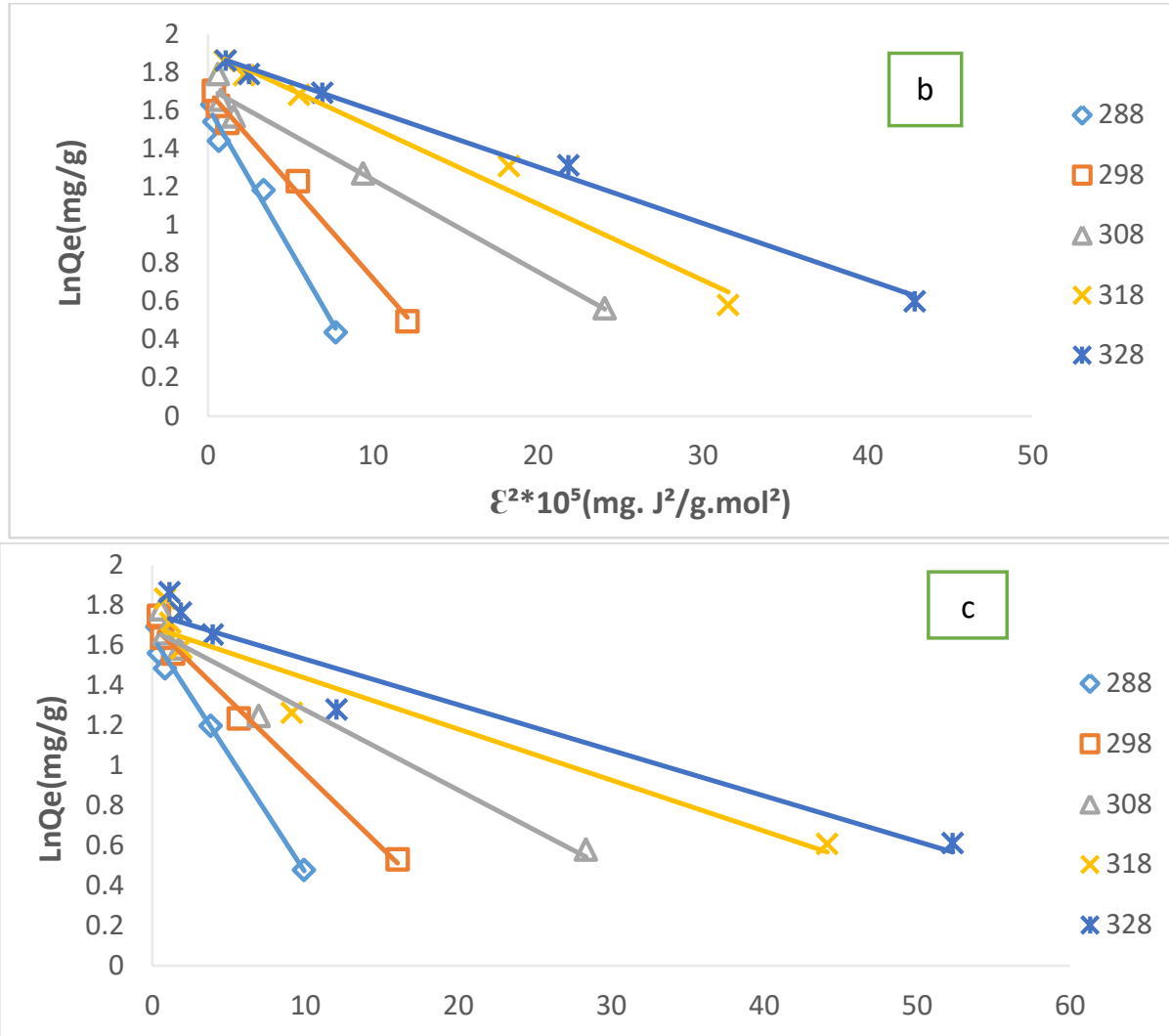

$\varepsilon^{2 *} 10^{5}\left(\mathrm{mg} . \mathrm{J}^{2} / \mathrm{g} \cdot \mathrm{mol}^{-1}\right)$

Figure16-D-R isotherm plots for the adsorption of MV6B dye onto (a) RC, (b) ACH, and (c) ACS at different temperatures.

Table 1- Equilibrium isotherm data for the adsorption of MV6B dye onto RC, ACH, and ACS at different temperatures.

\begin{tabular}{|c|c|c|c|c|c|c|c|c|c|}
\hline \multicolumn{5}{|c|}{ Langmuir } & \multicolumn{5}{|c|}{ Freundlich } \\
\hline \multirow{6}{*}{ RC } & $\begin{array}{l}\text { Temperatur } \\
\text { e } \quad(\mathbf{K})\end{array}$ & $\underset{\left(\mathbf{m g} \cdot \mathrm{g}^{-1}\right)}{\mathbf{Q}_{\mathbf{m}}}$ & $\begin{array}{c}\mathbf{K}_{\mathbf{L}} \\
(\mathbf{L} / \mathbf{m g})\end{array}$ & $\mathbf{R}^{2}$ & $\begin{array}{l}\text { Slope } \\
\left(1 / \mathbf{n}_{\mathrm{f}}\right)\end{array}$ & $\mathbf{n}_{\mathrm{f}}$ & $\begin{array}{c}\text { Interce } \\
\text { pt } \\
\mathbf{L n K}_{\mathrm{Fr}}\end{array}$ & $\begin{array}{c}\mathrm{K}_{\mathrm{Fr}}(\mathrm{mg} / \mathrm{g} \\
)\end{array}$ & $\mathbf{R}^{2}$ \\
\hline & 288 & 7.4570 & 0.5550 & 0.9819 & 0.4906 & 2.038 & 0.9086 & 2.4808 & 0.8882 \\
\hline & 298 & 7.3909 & 0.7260 & 0.9942 & 0.4478 & 2.233 & 1.0357 & 2.8170 & 0.9099 \\
\hline & 308 & 6.9930 & 1.4400 & 0.9988 & 0.3640 & 2.747 & 1.2545 & 3.5060 & 0.8925 \\
\hline & 318 & 7.6982 & 1.2400 & 0.9991 & 0.4071 & 0.456 & 1.3098 & 3.7054 & 0.9172 \\
\hline & 328 & 7.4738 & 2.1090 & 0.9995 & 0.3704 & 2.699 & 1.4748 & 4.3701 & 0.9725 \\
\hline \multirow{5}{*}{ ACH } & 288 & 7.5870 & 0.1430 & 0.9903 & 0.5675 & 1.762 & 0.1791 & 1.1961 & 0.8717 \\
\hline & 298 & 7.7570 & 0.1940 & 0.9881 & 0.5608 & 1.783 & 0.3827 & 1.4662 & 0.8700 \\
\hline & 308 & 7.1580 & 0.3350 & 0.9846 & 0.5037 & 1.985 & 0.6435 & 1.9031 & 0.9035 \\
\hline & 318 & 7.9617 & 0.5670 & 0.9952 & 0.5681 & 1.760 & 0.8439 & 2.3254 & 0.8190 \\
\hline & 328 & 8.5760 & 0.4390 & 0.9992 & 0.5309 & 1.883 & 0.9332 & 2.5426 & 0.8301 \\
\hline \multirow{4}{*}{ ACS } & 288 & 7.8490 & 0.1610 & 0.9824 & 0.5686 & 1.758 & 0.2698 & 1.3097 & 0.9021 \\
\hline & 298 & 8.0710 & 0.2340 & 0.9896 & 0.5568 & 1.795 & 0.4598 & 1.5837 & 0.9193 \\
\hline & 308 & 7.6680 & 0.2960 & 0.9904 & 0.5079 & 1.968 & 0.6344 & 1.8858 & 0.9611 \\
\hline & 318 & 8.1230 & 0.3450 & 0.9925 & 0.4994 & 2.002 & 0.7513 & 2.1197 & 0.9865 \\
\hline
\end{tabular}




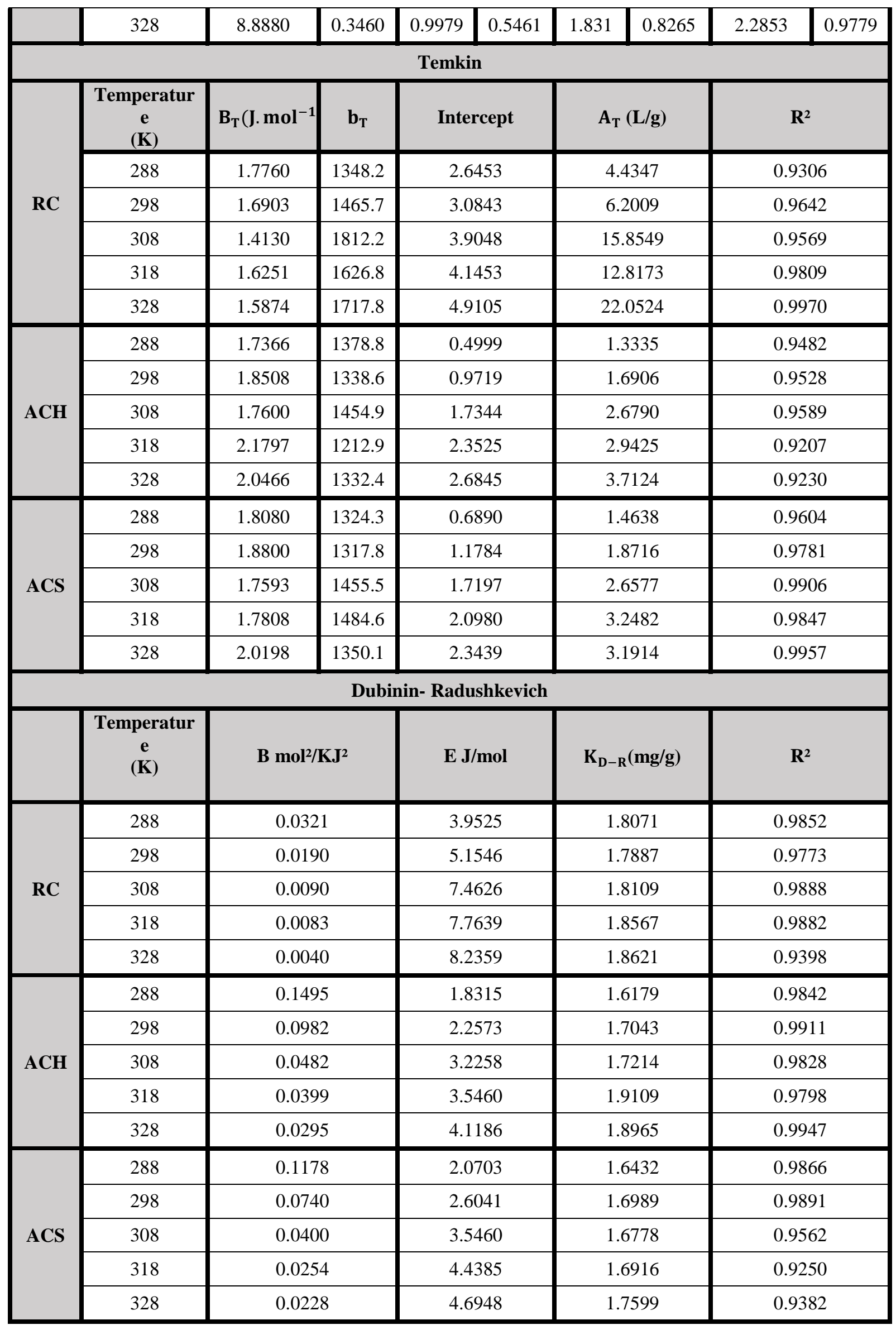


Table 2- Dimensionless equilibrium parameters for the adsorption of MV6B dye onto RC, ACH, and ACS at different temperatures.

\begin{tabular}{|c|c|c|c|}
\hline \multirow{2}{*}{ Temperature(K) } & $\underline{\mathbf{R C}}$ & $\underline{\mathbf{A C H}}$ & $\underline{\mathbf{A C S}}$ \\
& & $\underline{3}$ & \\
& & $\underline{\mathbf{R s}}$ \\
& & 0.4115 & 0.6230 \\
\hline 288 & 0.1526 & 0.5150 & 0.2994 \\
\hline 298 & 0.5793 & 0.2290 & 0.2524 \\
\hline 308 & 0.0649 & 0.1499 & 0.2240 \\
\hline 318 & 0.0746 & 0.1855 & 0.2155 \\
\hline 328 & 0.0452 & &
\end{tabular}

\section{6- Adsorption thermodynamic}

The thermodynamic parameters for the adsorption of MV6B were evaluated by using the following equations:

$$
\begin{aligned}
& \Delta \mathrm{G}=-\mathrm{RT} \operatorname{Ln} \mathrm{K}_{\mathrm{eq}} \\
& \mathrm{K}_{\mathrm{eq}}=\left[\frac{\mathrm{C}_{\mathrm{C}}-\mathrm{C}_{\mathrm{e}}}{\mathrm{C}_{\mathrm{e}}}\right]\left[\frac{\mathrm{V}}{\mathrm{M}}\right] \\
& \mathrm{LnK}_{\mathrm{eq}}=\frac{\Delta \mathrm{S}}{\mathrm{R}}-\frac{\Delta \mathrm{H}}{\mathrm{R}} \cdot \frac{1}{\mathrm{~T}}
\end{aligned}
$$

where $\mathrm{T}$ is absolute temperature $(\mathrm{K}), \mathrm{K}_{\mathrm{eq}}$ is the ability of adsorbate to retain and a measure of its movement within solution, $\mathrm{R}$ is the perfect gas constant (8.314 J.K- $\left.{ }^{-1} \mathrm{~mol}^{-1}\right), \mathrm{C}_{\mathrm{i}}$ and $\mathrm{C}_{\mathrm{e}}$ are the initial and equilibrium concentrations, respectively, of MV6B dye solution $(\mathrm{mg} / \mathrm{L}), \mathrm{M}$ is the weight of the adsorbent (g), and $\mathrm{V}$ is the volume solution of adsorbate in (L) [27]. The values of $\Delta \mathrm{H}^{\circ}{ }_{\mathrm{a}}$ and $\Delta \mathrm{S}^{\circ}{ }_{\mathrm{a}}$ can be estimated from the slope and intercept of the linear Vant's Hoff plot of $\mathrm{LnK}_{\mathrm{eq}} \mathrm{vs.} 1 / \mathrm{T}$, while the values of $\Delta \mathrm{G}_{\mathrm{a}}^{\circ}$ can be estimated from equation 7 [28] (Figure-17 a, b, and c). Thermodynamic data for the adsorption of MV6B dye onto RC, ACH, and ACS are shown in Table- 3. The negative values of the Gibbes free energy $\Delta \mathrm{G}^{\circ}{ }_{\mathrm{a}}$ confirm that the adsorption of MV6B dye onto clays is spontaneous. The positive values of $\Delta \mathrm{H}^{\circ}$ a confirm an endothermic nature for the sorption process, while the positive values of the entropy change $\Delta \mathrm{S}^{\circ}$ a suggest an increase in randomness at the interface between solid/solution, which is related to the increase in the degrees of freedom of the dye species [18].

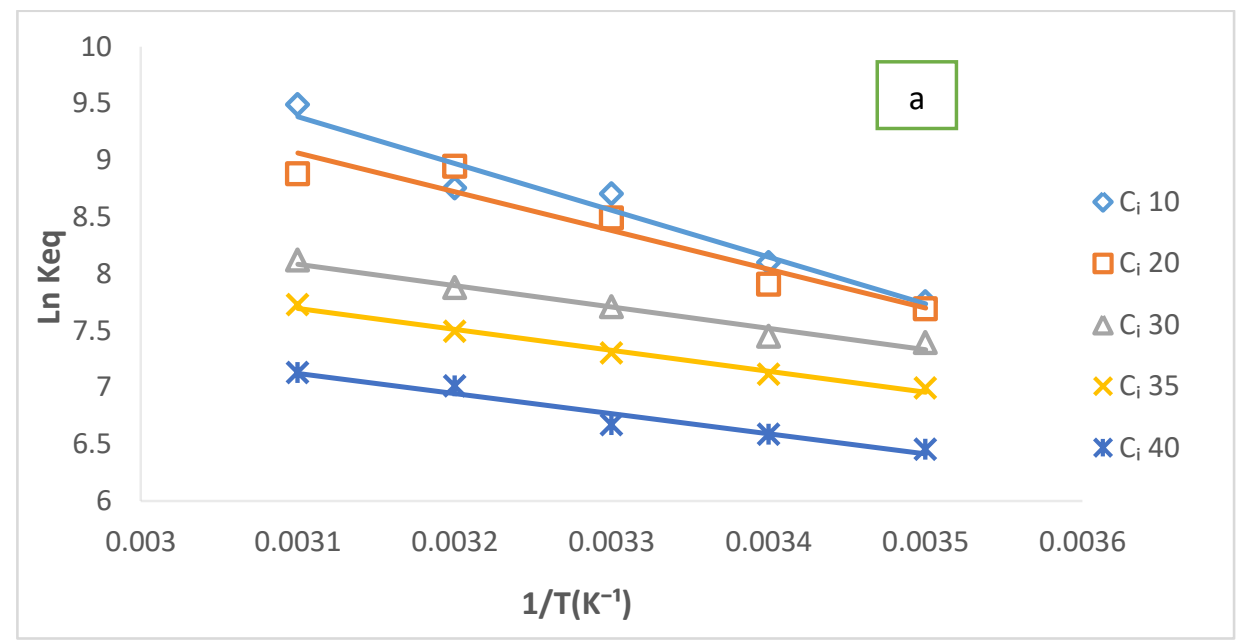



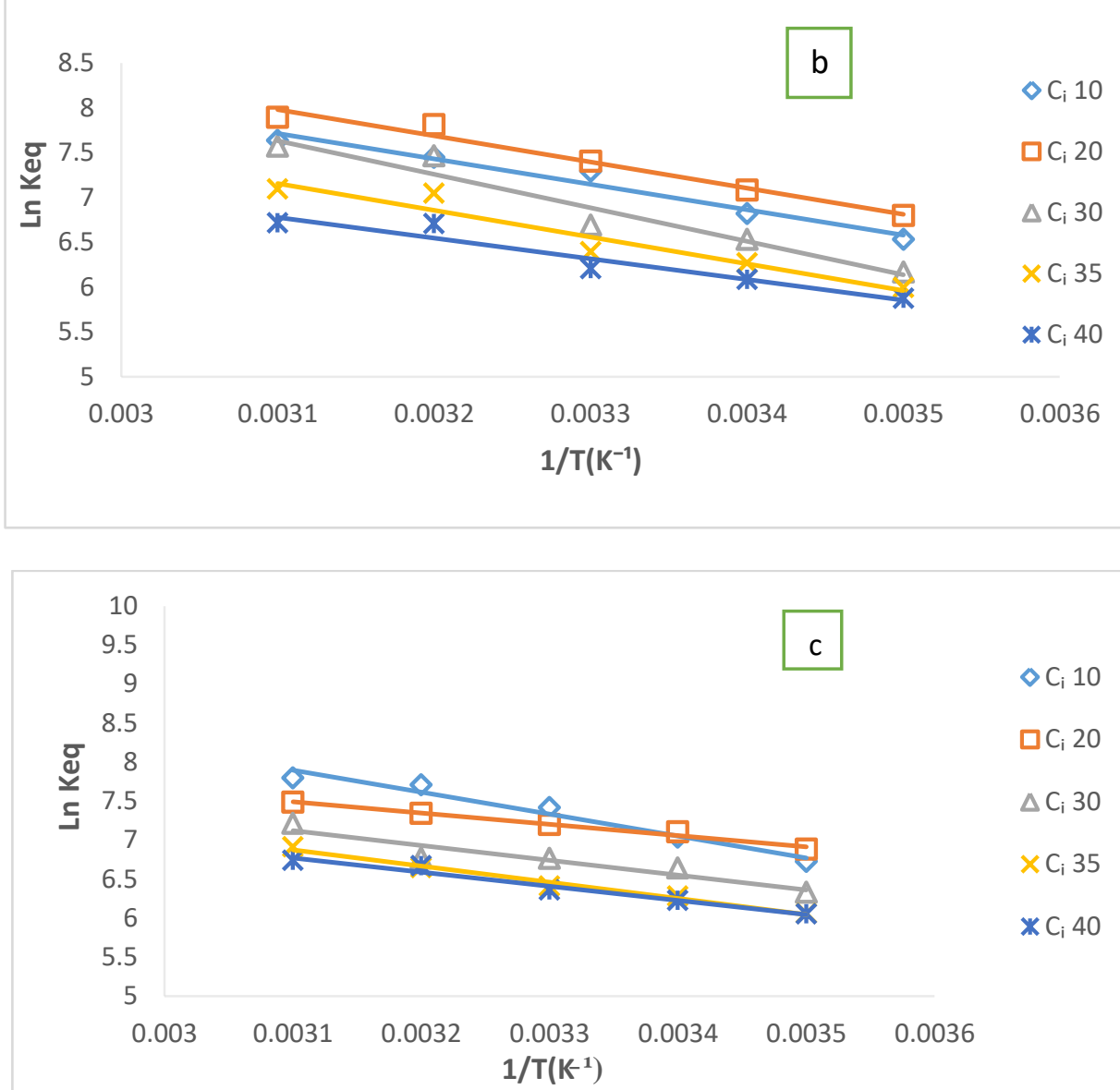

Figure17- Van't Hoff plots for the adsorption of MV6B dye onto (a) RC, (b) ACH, and (c) ACS at different temperatures.

Table 3-Thermodynamic parameters for the adsorption of MV6B dye onto raw clay and acid activated clays

\begin{tabular}{|c|c|c|c|c|c|c|c|c|}
\hline \multirow{5}{*}{$\mathrm{RC}$} & \multirow{2}{*}{$\mathrm{C}_{\mathrm{i}}(\mathrm{mg} / \mathrm{L})$} & \multirow{2}{*}{$\Delta \mathrm{H}(\mathrm{kJ} / \mathrm{mol})$} & \multirow{2}{*}{$\mathrm{S}(\mathrm{kJ} / \mathrm{mol})$} & \multicolumn{7}{|c|}{$(-) \Delta \mathrm{G}(\mathrm{kJ} / \mathrm{mol})$} \\
\cline { 2 - 9 } & 10.0 & 34.295 & 0.1843 & 18.56 & 20.06 & 22.28 & 23.14 & 25.87 \\
\cline { 2 - 9 } & 20.0 & 28.383 & 0.1633 & 18.41 & 19.58 & 21.73 & 23.64 & 24.21 \\
\cline { 2 - 9 } & 30.0 & 15.646 & 0.1157 & 17.70 & 18.45 & 19.73 & 20.83 & 22.13 \\
\cline { 2 - 9 } & 35.0 & 15.322 & 0.1114 & 16.74 & 17.62 & 18.70 & 19.81 & 21.07 \\
\cline { 2 - 9 } & 40.0 & 14.740 & 0.1049 & 15.45 & 16.31 & 17.07 & 18.53 & 19.43 \\
\hline \multirow{5}{*}{$\mathrm{ACH}$} & 10.0 & 23.545 & 0.1371 & 15.64 & 16.89 & 18.66 & 19.68 & 20.82 \\
\cline { 2 - 9 } & 20.0 & 24.268 & 0.1415 & 16.27 & 17.54 & 18.95 & 20.65 & 21.52 \\
\cline { 2 - 9 } & 30.0 & 31.086 & 0.1598 & 14.76 & 16.18 & 17.13 & 19.73 & 20.64 \\
\cline { 2 - 9 } & 35.0 & 24.759 & 0.1362 & 14.35 & 15.53 & 16.37 & 18.63 & 19.34 \\
\cline { 2 - 9 } & 40.0 & 19.197 & 0.1158 & 14.06 & 15.07 & 15.88 & 16.40 & 18.31 \\
\hline \multirow{5}{*}{$\mathrm{ACS}$} & 10.0 & 23.420 & 0.1382 & 16.09 & 17.42 & 18.98 & 20.37 & 21.25 \\
\cline { 2 - 9 } & 20.0 & 11.947 & 0.0993 & 16.48 & 17.60 & 18.43 & 19.40 & 20.41 \\
\cline { 2 - 9 } & 30.0 & 15.763 & 0.1080 & 15.15 & 16.45 & 17.32 & 17.90 & 19.66 \\
\cline { 2 - 9 } & 35.0 & 17.218 & 0.1105 & 14.50 & 15.55 & 16.40 & 17.56 & 18.84 \\
\hline & 40.0 & 15.073 & 0.1030 & 14.49 & 15.43 & 16.27 & 17.63 & 18.37 \\
\hline
\end{tabular}




\section{7- Conclusions}

Acid activation of clay mixture was successfully accomplished in the course of the investigation described. Both acid clays of ACH and ACS showed sufficient adsorption in respect to Methyl Violet 6B from aqueous solution, which may be related to the presence of different functional groups on their surfaces as well as their porous structure. These results lead to highest adsorption capacity obtained for the both types of acid-activated clays. The study of the impacts of the various variables revealed that the sorption process was dependent on clay dosage, agitation time, starting MV6B concentration, temperature, ionic strength, and $\mathrm{pH}$ values. Among the different adsorption isotherm models used, Langmuir model described better the uptake of MV6B dye by using ACH and ACS clays as adsorbents. Thermodynamic calculation indicated that the adsorption of MV6B on the clay samples was an endothermic and spontaneous process that occurs with the increase in the randomness.

\section{References}

1. Adeyemo, A.A., Adeoye, I.O. and Bello, O.S. 2015. Adsorption of Dyes Using Different Types of Clay: A review, Applied Water Science, 20(2): 453-568.

2. Ozcan, A.S., Erdem, B. and Ozcan, A. 2005. Adsorption of Acid Blue193 from Aqueous Solutions onto BTMA-Bentonite, Colloids and Surfaces A: Physicochemical and Engineering Aspects, 266(1-3): 73-81.

3. Bhatnagar, A. and Jain, A.K. 2005. A comparative Adsorption Study with Different Industrial Wastes as Adsorbent for the Removal of Caionic Dyes from Water, Journal of Colloid and Interface Science, 281(1): 49-55.

4. Adebowale, K.O., Owolabi, B.I. and Chigbundu, E.C. 2014. Removal of Safranin-O from Aqueous Solution by Adsorption onto Kaolinite Clay, Journal of Encapsulation and Adsorption Sciences, 4(3): 89-104.

5. Fungaro, D.A. and Magdalena, C.P. 2012. Adsorption of Reactive Red 198 from Aqueous Solution by Organo Zeolite from Fly Ash: Kinetic and Equilibrium Studies, International Journal of Chemical and Environmental Engineering Science, 3(3): 7-14.

6. Osman,A.I., Ahmed, A.T., Johnston, C.R. and Rooney, D.W. 2017. Physicochemical Characterization of Miscanthus and its Application in Heavy Metals Removal from Wastewaters, Environmental Progress and Sustainable Energy, 37(3): 1058-1067.

7. Zakaria R.M., Hassan, I., El-Abd, M.Z. and EI-Towil, Y.A. 2009. Lactic Acid Removal from Wastewater by Using Different Types of Activated Clay, Thirteen International Water Technology Conference, 13: 403-416.

8. Rizk, S.E. and Hamed, M.M. 2015. Batch Sorption of Iron Complex Dye, Naphthol Green B, from Wastewater on Charcoal, Kaolinite, and Tafla, Desalination and Water Treatment, 56(6): 111.

9. Mohamed, S.S. and Al-Heetimi, D.T.A. 2019. Adsorption of Methyl Violet Dye from Aqueous Solution by Iraqi Bentonite and Surfactant - Modified Iraqi Bentonite, Ibn Al Haitham Journal for Pure and Applied Sciences, 23(3): 28-42.

10. Sejie, F.P. and Tabbiruka,M.S. 2016. Removal of Methyl Orange (MO) from Water by Adsorption onto Modified Local Clay (Kaolinite), physical chemistry, 6(2): 39-48.

11. Lu, P., Chen, T., Liu, H., Li, P., Peng, S., Yang, Y. and Green, 2019. Preparation of Nanoporous Pyrrhotite by Thermal Treatment of Pyrite as an Effective Hg (II) Adsorbent: Preformance and mechanism, Minerals, 9(2): 1-17.

12. Vollpreeht, D., Fruhauf, S., Stocker, K. and Ellersdorfer, M. 2019. Ammonium Sorption from Landfill Leachates Using Natural and modified Zeolites: Pre-Testes for a Novel Application of the Ion Exchanger Loop stripping process, Minerals, 9(8):1-10

13. Eskhan, A., Banat, F., Selvaraj, M. and Abu Haija, M. 2019. Enhanced Removal of Methyl Violet 6B Cationic Dye from Aqueous Solutions Using Calcium Alginate Hydrogel Grafted with Poly (Styrene-co-Maleic Anhydride), Polymer Bulletin, 76(1): 175-203.

14. AL-Dabbagh, N.O.F. 2018. Minerolagy and Geochemistry of Injana and Mukdadiya Formations (Upper Miocene-Pliocene) in Zorbatiya area, east Iraq. M.Sc. Thesis, University of Baghdad, Baghdad, Iraq. 
15. Obiageli, A.R. 2017. Adsorption of Cationic Dye onto Low-Cost Adsorbent Synthesized from Bentonite Clay Part 1. Kinetic and Thermodynamic Studies, Journal of Chemical Technology and Metallurgy, 52(3): 491-504.

16. Allam, K., Gourai, K., EL Bouari, A., Belhorma, B. and Bih, L. 2018. Adsorption of Methylene Blue on Raw and Activated Clay: Case Study of Bengurir Clay, Journal of Materials and Environmental Sciences, 9(6): 1750-1761.

17. Miyah,Y., Lahrichi, A., Idrissi, M., Anis, K. and Kachkoul, R. 2017. Removal of Cationic Dye “ Crystal Violet "in Aqueous Solution by the Local Clay, Journal of Materials and Environmental Sciences, 8(10): 3570-3582.

18. Collins, O.N., Elijah, O.C. and Okechhukwu, O. 2019. Adsorption of a Dye (Crystal Violet) on an Acid Modified on- Conventional Adsorbent, Journal of Chemical Technology and Metallurgy, 54(1): 95-110.

19. Lamayi, D.W., Shehu, Z. and Kwarson, P.S. 2018. Aqueous Phase Removal of Fluoride as Fluorosis Agent Using Montmorillonite Clay as Natural Nano Adsorbent, Nano chemistry Research, 3(2): 219-226.

20. Zhang, Y., Wang, D., Liu, B., Cao, X., Xu, W. and Liang, P. 2013. Adsorption of Fluoride from Aqueous Solution Using Low-Cost Bentonite/ Chitsan Beads, American Journal of Analytical Chemistry, 4(7): 48-53.

21. Al-Rudaini, K.A. 2017. Adsorption Removal of Rhodamine-B Dye from Aqueous Solution Using Rhamnus Stone as Low Cost Adsorbent, Journal of Al-Nahrain University, 20(1): 32-41.

22. Khalid, E., Laachach, A., Alaoui, A. and Azzi, M. 2011. Removal of Methyl Violet From Aqueous Solution Using a Stevensite-Rich Clay from Morocco, Applied Clay Science, 54(1): 9096.

23. Bouatay, F., Dridi, S. and Mhenni, M.F. 2014. Valorization of Tunisian Pottery Clay onto Basic Dyes Adsorption, International Journal of Environmental Researches, 8(4): 1053-1066.

24. Ogbaji, E.G., Hikon, B.N., Sheckhar, N.G., Yerima, E.A., Mavis, O., Ekirigwe, O. and Ayodeji, A.F. 2019. Synergistic Study of Hydroxyiron (III) and Kaolinite Composite for the Adsorptive Removal of Phenol and Cadmium, International journal of Environmental Chemistry, 3(1): 3042.

25. Emeniru, D.C., Onukwuli,O.D., Wodu,P.D. and Okoro, b.I. 2015. The Equilibrium and Thermodynamics of Methylene Blue Uptake onto Ekowe Clay; Influence of Acid Activation and Calcination, International Journal of Engineering and Applied Sciences, 2(5): 17-25.

26. Atiya, M.A., M-Ridha, M.J. and Saheb, M.A. 2020 .Removal of Aniline Blue from Textile Wastewater Using Electrocoagulation with the Application of the Response Surface Approach, Iraqi Journal of Science, 61(11): 2797-2811.

27. Bendaho, D., Driss, T.A. and Bassou, D. 2017. Adsorption of Acid Dye onto Activated Algerian Clay, Bulletin of the Chemical Society of Ethiopia, 31(1): 51-62.

28. Sumaila A., Ndamitso M.M., Iyaka Y.A., Abdulkareen A.S., Tijani J.O. and Idris M.O. 2020. Extraction and Characterization of Chitosan from Crab Shells: Kinetic and Thermodynamic Studies of Arsenic and Copper Adsorption from Electroplating Wastewater, Iraqi Journal of Science, 61(9): 2156-2171. 